João Carlos Vitorino PEREIRA

\title{
LE VILLAGE ANARCHIE DANS UM AMOR ANARQUISTA, DE MIGUEL SANCHES NETO : L'(IM) POSSIBLE UTOPIE ANARCHISTE ENTRE REVE ET CAUCHEMAR*
}

João Carlos Vitorino PEREIRA**

Foi um livro que me deu muita alegria escrever, pois fala de um tempo de sonhos. Anarquistas e imigrantes, cada um de sua forma, souberam conjugar este sonho. De vez em quando, visito a região da Colônia Cecília, onde não sobrou quase nada, e bebo um vinho produzido na região pelos descendentes - um vinho colono, forte, sem requinte, e revivo assim a experiência do dr. Rossi. ${ }^{1}$

\section{INTRODUCTION}

Um Amor Anarquista ${ }^{2}$ est un roman de Miguel Sanches Neto inspiré de l'expérience de Giovanni Rossi, fondateur de la colonie Cecília. Cette communauté anarchiste, composée surtout d'Italiens mais aussi de deux Français et d'un Espagnol, s'est implantée au début du mois d'avril 1890 dans le Paraná ${ }^{3}$, à dix-huit kilomètres au sud de Palmeira, petite ville brésilienne dont Rossi, selon Isabelle Felici,

recense tous les avantages [...], de l'église au bureau de poste et télégraphe, en passant par le club littéraire et la société de théâtre, et surtout '[...] une pléiade de personnes remarquables, dont quelques-unes ont fait leurs études aux Etats-Unis d'Amérique

\footnotetext{
${ }^{1}$ Extrait d'un courriel de l'auteur que nous avons reçu le 22 mai 2007.

${ }^{2}$ Miguel Sanches NETO, Um Amor Anarquista, $2^{\mathrm{e}}$ éd., Rio de Janeiro, Editora Record, 2005 ; toutes nos citations sont tirées de cette édition.

${ }^{3}$ Miguel Sanches Neto, né en 1965, est originaire du Paraná; voir José Luís Pires LARANJEIRA, " Miguel Sanches Neto - O italiano anarquista ", Jornal de Letras, Artes e Ideias, n 947, 17-30 janv. 2007, p. 17.

* Ce texte est la version largement augmentée de notre communication présentée au colloque international intitulé « Utopies, enchantements, hybrités dans la ville ibérique et latino-américaine ", qui s'est tenu à l'Université Lumière - Lyon II du 28 février au $1^{\text {er }}$ mars 2008 (actes à paraître en 2008 dans la revue Textures de l'Université Lumière - Lyon II)

${ }^{* *}$ Université de Lyon II
} 
Le Village Anarchie Dans UN AMOR ANARQUISTA, de Miguel Sanches Neto: ...

du Nord ou en Europe, mais qui font toutes montre de beaucoup d'intelligence et de la plus exquise des courtoisies'. ${ }^{4}$

Rossi s'installe donc avec les autres colons de la Cecília à proximité de cette ville policée, qui contrastera avec le village Anarchie, sorte de cité parfaite qui ne pouvait voir le jour que dans le Nouveau Monde, et plus précisément au Brésil, où tout semblait possible, l'eldorado brésilien se transformant peu à peu en cauchemar pour tous les membres de cette communauté, y compris pour son fondateur, le vétérinaire Giovanni Rossi, féru d'agronomie.

Le Vieux Continent, quant à lui, n'était guère ouvert à la nouveauté, ce qui valut bien des déboires à cet anarchiste de Pise. En effet, Rossi fonde en 1887 une colonie coopérative agricole, la Cittadella, qu'il ne parviendra pas à transformer en colonie socialiste; après cet échec, il crée en 1888 une union de travailleurs. C'est que, d'après le dix-neuviémiste Robert Schnerb, l'Italie connaît de graves difficultés :

Les analogies ne manquent pas entre les deux péninsules, ibérique et italienne. [...]. Une paysannerie très pauvre, arriérée, sans instruction, victime de la grande propriété et du manque de capitaux. Un régionalisme entretenu par un morcellement prolongé, par une intense vie citadine aux horizons étroits. Une opposition entre le Nord et le Midi [...].

$[$.

....]

[...]. En somme les contrastes augmentent plutôt. Le Midi se plaint toujours d'être trop imposé et la détresse de ses foules rurales les jette en masse sur les chemins de l'émigration. [...]. Mais à la misère paysanne et à la question agraire s'ajoutent la misère et la question ouvrières. ${ }^{5}$

Dans le récit de Sanches Neto, on trouve bien et des paysans, et des ouvriers. Ainsi, la misère paysanne et ouvrière favorise l'émigration et l'intérêt pour le socialisme. C'est alors qu'essaiment les utopies communautaires qui, selon un autre spécialiste du XIX

${ }^{4}$ Isabelle FELICI, La Cecilia - Histoire d'une communauté anarchiste et de son fondateur Giovanni Rossi, Lyon, Atelier de Création Libertaire " Commune Mémoire », 2001, p. 37.

${ }^{5}$ Robert SCHNERB, Le XIX siècle - L'apogée de l'expansion européenne, Paris, P.U.F. "Quadrige », 1993 , p. $270-271$. 
siècle, Philippe Muray, " constituent l'une des constantes les plus marquantes du $19^{e}$ " $^{6}$; en effet, "De 1825 à 1914, on a dénombré à peu près cent trente-sept tentatives notables de communautés. ${ }^{7}$; ces utopies communautaires seraient, ajoute ce spécialiste, le fruit d'une " rencontre invisible de l'occulte et du socialisme faisant jonction souterraine $»^{8}$. S'agissant de l'Italie, Philippe Muray nous apprend qu'en 1878, « dans une Italie où les Etats du pape ont été réduits à la portion congrue, $[\ldots]$ un certain David Lazzaretti $[. .$. fait hisser le drapeau de la République utopique sur le mont Amiata, descend dans la plaine avec une petite armée de fidèles, rencontre les carabiniers et finit criblé de balles... ${ }^{9}$. Alain Pessin, quant à lui, évoque le premier coup d'éclat des anarchistes italiens, dans la province du Bénévent :

En avril 1877, une trentaine d'hommes armés, organisés par Cafiéro, Malatesta et Ceccarelli, envahirent plusieurs villages de cette province, y prêchèrent l'anarchie, obligeant de surcroît les curés à rappeler les principes de la fraternité évangélique, se rendirent maîtres des mairies, brûlant les registres de fermage et d'impôts, proclamant l'égalité. Après quelques heurts, quelques coups de feu échangés avec la police, ils durent se réfugier dans la montagne, et bientôt se rendre, épuisés de faim et de froid. ${ }^{10}$

La répression étatique exercée en Europe pousse donc les fervents utopistes comme Giovanni Rossi à partir pour l'Amérique, perçue comme « un continent encore presque vierge, donc authentique et sans péché $"{ }^{11}$ C'est que dès sa découverte, le Nouveau Monde apparaît, aux yeux des Européens, comme " une terre inconnue où tout est encore possible, [...] comme un possible champ de réalisation d'une $[. .$.$] république de rêve, une Utopie ~^{12}$, ou encore " comme la

\footnotetext{
${ }^{6}$ Philippe MURAY, Le XIX $X^{e}$ siècle à travers les âges, 2 éd., Paris, Gallimard " Tel », 1999, p. 232

${ }^{7}$ Ibid., p. 233.

${ }^{8}$ Ibid., p. 232.

${ }^{9}$ Ibid., p. 235.

${ }^{10}$ Alain PESSIN, La rêverie anarchiste (1848-1914), Lyon, Atelier de Création Libertaire, 1999, p. 39

${ }^{11}$ Philippe MURAY, op. cit., p. 233.

12 Fernando AINSA, "La découverte de l'autre et l'invention de l'utopie ", Europe "L'invention de l'Amérique ", n 756 , avril 1992, p. 48.
} 
Le Village Anarchie Dans UN AMOR ANARQUISTA, de Miguel Sanches Neto: ...

somme des perfections, comme une authentique Terre promise $»^{13}$; ainsi, sur « ces terres vierges et sans histoire [...] on pouvait (mieux : on devait) refaire le monde occidental ». En somme, le « mythe de la Terre promise se nourrit de cette idée et joue un rôle fondamental dans la représentation que se font du Nouveau Monde les pionniers et les émigrants, non seulement de l'époque coloniale, mais encore de nos jours. ${ }^{14}$. Ce que ne dit pas Fernando Ainsa, c'est que la conquête du Nouveau Continent repose aussi, comme le montre fort bien Um Amor Anarquista, sur le mythe de l'homme nouveau, dans lequel s'est probablement métamorphosé le mythe du bon sauvage. Par ailleurs, le brésilien Teixeira Coelho fait observer que « o novo mundo não produziu propriamente novas concepções utópicas ; apenas tentou realizá-las. ${ }^{15}$; en réalité, comme le dit Teixeira Coelho, le Nouveau Continent est un monde doublement nouveau ${ }^{16}$ pour les utopistes car ils ne recherchaient pas en Amérique seulement de nouvelles terres, loin d'une Europe en dégénérescence, dégénérescence qui pourrait nuire, par contamination, à la réalisation de leur projet, mais la possibilité de créer une société et un homme nouveaux.

C'est dans ce contexte européen que le Dr. Rossi se tourne vers le Nouveau Monde pour mener à bien son projet de fonder une colonie communautaire. A ce stade de notre introduction, il nous faut préciser que cet Italien avait publié en 1878 un roman, Un comune socialista, où il imagine une communauté idéale ${ }^{17}$; pour passer de la théorie à la pratique, il établira une colonie socialiste au Brésil, la colonie Cecília, du nom d'un personnage de son roman ${ }^{18}$. Cette expérience anarchiste durera, cahin-caha, d'avril 1890 à avril $1894^{19}$. C'est le parcours semé d'embûches de cet homme et de ses disciples, plus ou moins enthousiastes, que raconte Miguel Sanches Neto dans son livre. Notons, enfin, que l'utopie communautaire à l'œuvre dans la colonie Cecília s'apparenterait à ce Philippe Muray appelle le "socialisme agricole ", autrement dit le « remembrement

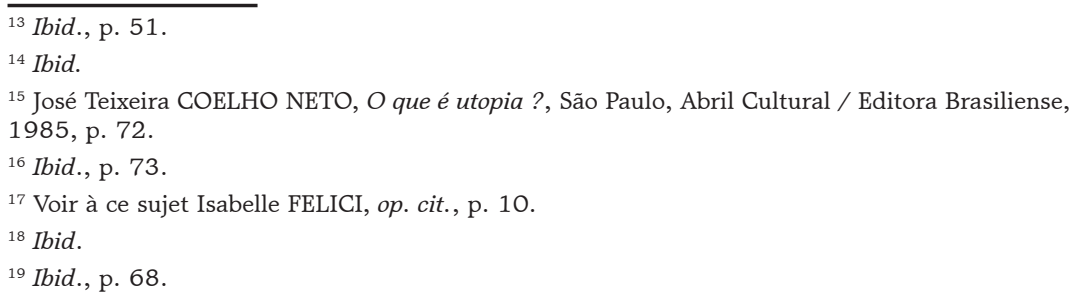
Disponível em <http://www.uepg.br/olhardeprofessor> 
de l'occulto-socialisme dans l'espace rural. $»^{20}$. Teixeira Coelho, qui distingue au Brésil au moins trois types d'utopie - les utopies millénaristes païennes précoloniales, les utopies messianiques d'inspiration religieuse et les utopies anarcho-communistes ${ }^{21}$-, rappelle que la colonie Cecília, d'inspiration fouriériste, est la plus importante des communautés anarchistes brésiliennes ; il en cite une deuxième : la colonie Vapa, fondée vers 1930 par des immigrants d'Europe de l'Est, à Assis, dans l'Etat de São Paulo22 .

\section{LA COLONIE CECILIA : UNE TERRE PROMISE POUR UN HOMME NOUVEAU DANS UNE CITE IDEALE}

Avant de poursuivre plus avant l'analyse, notons que, du point de vue de la composition du récit, deux perspectives se superposent dans Um Amor Anarquista, celle du narrateur extérieur à l'action, statut qui ne l'empêche pas parfois de lire dans les pensées des personnages, et celle de Giovanni Rossi, qui, au début du roman, s'impose comme narrateur ; il s'agit dans ce cas d'un narrateur homodiégétique. Ainsi, l'auteur croise les points de vue, le récit du narrateur hétérodiégétique étant entrecoupé de lettres écrites essentiellement par le Dr. Rossi, et ce jusqu'à la fin du livre. En somme, nous avons affaire à un roman hybride, en partie épistolaire : on passe donc constamment de la partie narrative et romanesque à la partie épistolaire et doctrinaire, autrement dit de l'expérience communautaire, de la pratique, à la théorie, que Giovanni Rossi expose dans ses lettres de propagande. Ce va-et-vient d'un plan à l'autre, tout au long du roman, permettra au lecteur de mieux se rendre compte du hiatus qui existe entre la pratique et la théorie, hiatus qui ne fera que s'aggraver au fil des pages car Um Amor Anarquista n'est pas un roman utopique mais un roman nostalgique sur une utopie dont la réalisation s'est soldée par un échec. Contrairement au genre utopique, qui implique une fin heureuse ${ }^{23}$, ce roman, après une phase ascendante, est placé sous le

\footnotetext{
${ }^{20}$ Philippe MURAY, op . cit., p. 234.

${ }^{21}$ Voir José Teixeira COELHO NETO, op. cit., p. 77-82.

${ }^{22}$ Ibid., p. 82.

${ }^{23}$ José V. de Pina MARTINS, dans son Utopia III, qui offre une mise en abyme ludique et pénétrante de la célèbre Utopie, récit considéré comme un paradigme du genre, met en scène D. Miguel das Utopias, descendant du portugais Raphaël Hythlodée, qui décrit la société utopienne imaginée par Thomas More; Miguel Hytlodeu relate lui aussi la vie en Nouvelle Utopie. Il précise que son exposé est un éloge d'une société idéale : «- Não sei se foi suficientemente arguto para notar -
} 
Le Village Anarchie Dans UN AMOR ANARQUISTA, de Miguel Sanches Neto: ...

signe de la dégradation. La perspective polyphonique adoptée dans la partie narrative nuance le discours monologique de l'idéologue Giovanni Rossi, dont elle altère la portée ; cette technique narrative favorise une lecture récursive qui amène le lecteur à réinterpréter le récit et à relativiser les propos contenus dans la partie épistolaire, plus partisane, raison pour laquelle le narrateur hétérodiégétique prend assez vite le relais de la narration.

En utopiste, le Dr. Rossi cherche une terra incognita pour construire une cité idéale autarcique prophylactiquement éloignée de la civilisation ${ }^{24}$ : ce devait être l'Uruguay ${ }^{25}$ mais ce sera finalement le Brésil (p. 17), ou plus exactement un endroit à l'intérieur des terres, à la frontière entre le Paraná et l'Etat de Santa Catarina. Rossi participe donc à la conquête héroïque de cette terre brésilienne, encore relativement vierge, qui devient un espace mythique et utopique et le lieu par excellence où pourrait s'épanouir l'utopie anarchiste ${ }^{26}$ au milieu d'une nature généreuse, mais surtout sauvage, indomptée et libre. Ce roman de Miguel Sanches Neto convoque d'entrée de jeu l'imaginaire collectif brésilien qui, d'après Gilbert Durand, plonge ses racines dans la gigantesque terre brésilienne, laquelle apparaît toujours associée à la féminité 27 : dans ce " país tão grande e com tantas oportunidades » (p. 108), il y a encore " tanta terra sem dono » (p. 111).

Il s'agit d'une " terra agricultável » (p. 219) à connotation résolument positive, où tout se transforme miraculeusement, où tout se

observou D. Miguel - que se trata de um esboço de algum modo apologético. Não se referem em esboços históricos desse tipo as experiências falidas, que não marcam construtivamente as pátrias. » (Lisbonne, Editorial Verbo, 1998, p. 316 ; voir aussi p. 319). Le récit utopique se présente donc comme un récit apologétique.

${ }^{24}$ Pour parcourir les dix-huit kilomètres qui séparaient la colonie Cecília de la ville de Palmeira, il fallait quasiment quatre heures, comme le note le narrateur principal (p. 42).

${ }^{25}$ Des communautés anarchistes s'établirent en Argentine, au Pérou et en Uruguay ; voir à ce sujet Fernando AINSA, "Utopie, terre promise, émigration et exil », Diogène, n 119, 1982, p. 53.

${ }^{26}$ Alain PESSIN préfère parler de rêverie anarchiste car l'anarchisme ne saurait se réduire à une doctrine ou à un système : c'est, au contraire, une pensée mouvante, et surtout un sentiment diffus, assez romantique, un état d'âme en somme (op. cit., p. 18, 20, 24, 49, 213, 214). L'anarchisme s'oppose donc à l'utopie, qui propose un avenir organisé, un système rigide, cohérent, normatif (ibid., p. 24, 102, 103); si nous parlons d'utopie anarchiste, c'est parce que l'anarchisme, comme l'utopie, est profondément motivé par le rêve d'une vie nouvelle et heureuse, ainsi que le reconnaît Alain Pessin (ibid., p. 24). Pour une définition synthétique de l'anarchisme et de ses trois variantes, communiste ou collectiviste, individualiste et anarcho-syndicaliste, voir, par exemple, Alix LARGE, L'esprit libertaire du surréalisme, Lyon, Atelier de Création Libertaire, 1999, p. 20-23.

${ }^{27}$ Voir à ce sujet Gilbert DURAND, "Lointain Atlantique et prochain tellurique, imaginaire lusitanien et imaginaire brésilien ", in Champs de l'imaginaire, textes réunis et présentés par Danièle Chauvin, Grenoble, ELLUG « Ateliers de l'imaginaire », 1996, p. 183-184, 186. 
régénère, y compris l'homme, comme nous le verrons. Les qualificatifs pour caractériser cette terre brésilienne ne manquent pas : " terra fértil » (p. 102) " nova e maravilhosa terra » (p. 70). Ces « campos sem dono » (p. 70) font rêver ces immigrants italiens qui pourront ainsi « viver longe da opressão dos patrões » (p. 70). Mais il s'agit d'une nature sauvage que seul un travail harassant permettra de domestiquer (p. 168) ; le côté sauvage de ces «terras ditas selvagens » (p. 33) est néanmoins apprécié des anarchistes, qui ne cachent pas « o prazer de quem vê a natureza render-se à força humana » (p. 36), et « a alegria discreta de quem vence a natureza » (p. 168).

Cette utopie en voie de réalisation - «nosso projeto é deixar a teoria em nome da prática » (p. 32) - ne sera donc pas une utopie urbaine, le changement de société préconisé par Rossi passant par un retour à la nature. De la civilisation, notion fort controversée au $\mathrm{XIX}^{\mathrm{e}}$ siècle, par Fourier ${ }^{28}$, entre autres, Rossi ne retient que ce qui peut aider sa communauté à transformer cet enfer vert en paradis luxuriant : "O mato crescia e ia sufocando as hortaliças, e só as hortaliças deviam prosperar, as ervas daninhas tinham que ser erradicadas, era para isso que o homem tinha inventado as técnicas agrícolas, para isso servia a civilização, para isso eu estava ali. » (p. 25). Il fallait donc vaincre la nature pour " tirar dela o seu sustento » (p. 168) afin que ces terres sauvages n'incitent pas les hommes « a abandonar aquele chão, julgando-as invencíveis » (p. 25). Pour servir cet idéal rural, lié à la notion de paradis perdu, Rossi préfère recruter des agriculteurs : "Uns são operários, mas a maioria é da agricultura, todos convencidos da urgência de acabar com os patrões, e darão novo ritmo ao trabalho e ao socialismo na Cecília. » (p. 86) ; ouvriers des villes et ouvriers des champs composent donc la Cecília. Le deuxième groupe est par conséquent mieux préparé à la vie dans une communauté agricole car « estava acostumado à vida do campo e tinha uma disposição muito maior » (p. 96).

On remarquera également que ces terres lointaines deviennent un espace mythique : la « luminosidade tropical » et le « verde das matas » (p. 9) en font un cadre paradisiaque pour qui vient « de um país apagado »(p. 18). Ces immigrants idéalisent, comme il se doit,

${ }^{28}$ Cf. Paul RICEUR : "L'utopie est l'image renversée de ce que nous voyons dans la 'civilisation', terme péjoratif qui désigne chez Fourier la société dans son ensemble. » ("Fourier », in L'idéologie et l'utopie, trad. par Myriam Revault d'Allonnes et Joël Roman, Paris, Seuil « La couleur des idées ", 1997, p. 396). 
Le Village Anarchie Dans UN AMOR ANARQUISTA, de Miguel Sanches Neto: ...

leur terre d'élection ${ }^{29}$ où les villes portent des noms qui font rêver : Ilha das Flores, Porto Alegre et Palmeira sont des noms à consonance utopique $^{30}$ et ces lieux sont d'ailleurs connotés positivement dès le début du récit, dans la première lettre de Rossi, datée d'avril 1890 (p. 17-20).

Cette " terra tão acolhedora que é nossa Palmeira » (p. 102) attire de nombreux Italiens, écrira-t-il dans une autre lettre ; l'adjectif possessif « nossa » montre que le Brésil est devenu leur pays d'adoption, leur nouvelle patrie. La façon dont Rossi cherche à débarrasser rageusement le sol des mauvaises herbes traduit inconsciemment le désir d'une « terra livre de pragas » (p. 25), d'un monde de pureté : « Lá, na distância, não tinha mato, era tudo abstração, espaço ilusório, campos pacíficos de idealismo cromático. » (p. 26) ; l’illusion utopique produit son effet mais, comme le lui fait remarquer un membre pragmatique de la Cecília, Adele, ses mains calleuses " Não podem limpar o mundo. » (p. 26). Mais à quoi bon nettoyer la terre ? " - Talvez apenas para acreditar. » (p. 26), répond Adele : en travaillant sans cesse cette terre exubérante, Rossi et consorts s'accrochent en quelque sorte à l'espérance utopique dans un monde parfait et harmonieusement chromatique ; ils veulent croire que tout est possible. Il faut donc arracher les mauvaises herbes, au propre comme au figuré, car l'espace utopique est le locus amœnus par excellence : dans ce qui apparaît au début comme un enfer vert, " as ervas daninhas tinham que ser erradicadas » (p. 25), pense Rossi, dont le « desejo de destruir as invasoras » est viscéral (p. 25) ; autrement dit, il ne faudrait pas que le " desespero de existir das ervas daninhas " (p. 92) l'emporte. Au symbolisme des mauvaises herbes ${ }^{31}$, évident dans un tel contexte, s'oppose celui de la bonne semence : « deveria nascer apenas o que semeamos, e não esta outra semente que ninguém plantara, mas que sobrevive na terra, em grande quantidade, essa semente eterna. » (p. 25). Dans une de ses lettres, Rossi écrit que ces « vastos [...] campos sem dono » réclament l'intervention de

\footnotetext{
${ }^{29}$ Cf. Fernando AINSA : "L'utopie de l'espace est donc toujours attachée à un territoire idéalisé par la distance [...]. » (« Utopie, terre promise, émigration et exil », art. cit., p. 57).

${ }^{30}$ D'après Fernando AINSA, ces noms utopiques « donnent une existence 'objective' à l'utopie " (ibid., p. 63).

${ }^{31}$ Cf. Éloïse MOZZANI : « Une tradition veut aussi que les mauvaises herbes viennent d'une malédiction de Dieu lorsque Adam lui désobéit : l'homme aura beau les arracher, il n'en sera jamais délivré. " (Le livre des superstitions - Mythes, croyances et légendes, Paris, Club France Loisirs, 1999, p. 1420). 
" quem os revolucione, ocupando-os e tornando-os produtivos» (p. 70). Le verbe " revolucione " revêt ici une double signification car il s'agit d'ensemencer la terre mais aussi de semer la bonne parole révolutionnaire d'un côté et de l'autre de l'océan Atlantique, raison pour laquelle Rossi, " o ideólogo » (p. 178), se présente comme un «propagandista desta nova e maravilhosa terra » (p. 70). Dans une lettre, il écrit d'ailleurs que " descobriu que pátria não é onde nascemos, mas onde deixamos boas sementes. " (p. 103). Comme tout utopiste, Rossi est en quête de pureté et de perfection ; il appartient à la "raça dos puros, dos generosos, dos idealistas " (p. 177), et cherche à concrétiser son " sonho da sociedade perfeita » (p. 186) : la Cecília doit par conséquent devenir une « Colónia exemplar » (p. 193). Celle-ci présente tous les traits utopiques de la cité radieuse : "O clima aqui corre magnífico, com água e sol na quantidade certa, e as plantas agradecem tingindo a paisagem com cores gordas. » (p. 85), écrit Rossi dans une de ses lettres.

Le merveilleux irrigue l'imaginaire utopique ${ }^{32}$, si bien que le narrateur autodiégétique, Rossi, a le sentiment de vivre un rêve d'enfant :

[...] Benedetti e eu fomos tomar posse das terras no dia 8 de Abril. Era um campo circundado de matas, onde havia uma única e solitária casinha de madeira, abandonada ao lado de uns pés de laranja e de quatro palmeiras altas. A casa quase de brinquedo fortaleceu o sentimento de que estávamos dentro de nosso sonho juvenil. [...]

Na primeira noite, sem ter onde dormir, arrumamos uma cama com capim verde. Pacificados com o cheiro forte de mato, passamos a noite neste território livre [...]. (p. 20)

Le primitivisme de la scène fait penser à une robinsonade, qui présente des analogies avec l'utopie ${ }^{33}$ et où l'individu doit tout in-

\footnotetext{
${ }^{32}$ Cf. Jean MONTENOT : « [...] le recours aux catégories du 'féerique' et du 'merveilleux' n'est pas absolument exclu de certains récits utopiques. Mais, on peut dire que ces catégories ne sont pas consubstantielles à une définition un peu stricte du genre. Si féerie il y a, le plus souvent, c'est à cause de la sécurité qu'inspire cette société, contre-point [sic] de celle dans laquelle l'auteur du récit utopique vit et qu'il critique. " ("Une société sans pensée utopique est-elle concevable? ", p. 8-9, version électronique in http://www.sens-public.org/article.php3?id_article $=56$, page consultée le 27 juillet 2007.

${ }_{33}$ S'agissant d'une aventure individuelle, il faut cependant exclure les robinsonades du genre utopique, comme le fait observer Jean MONTENOT (ibid., p. 8). Ces dernières, d'après Georges
} 
Le Village Anarchie Dans UN AMOR ANARQUISTA, de Miguel Sanches Neto: ...

venter en partant de rien ; en effet, Rossi et ses compagnons donnent le sentiment de s'isoler dans un paradis entouré de verdure - « um campo circundado de matas »-, autrement dit dans une sorte d'insularité : Jean-Louis Comolli présente d'ailleurs la Cecília comme une " île d'anarchie entourée par le Brésil " ${ }^{34}$. D'après Alexandre Cioranescu, l'utopie « a besoin d'isolement et d'étanchéité, pour pouvoir suivre ses expériences avec toute l'asepsie d'un laboratoire, à l'abri du danger de contamination ${ }^{35}$.

On retiendra, dans cette citation, l'expression " território livre ", révélatrice d'une rêverie, d'un imaginaire anarchiste. Il est à remarquer qu'un membre de la Cecília rechigne à domestiquer la nature vierge et luxuriante qui l'entoure et qui offre ainsi une image de paradis. Lorenzo est en effet un contemplatif et, en parfait anarchiste, il refuse de dominer la nature ${ }^{36}$; c'est le narrateur hétérodiégétique qui reproduit le discours intérieur de ce personnage :

Ele queria passear pelas matas sem interferir em nada, apenas um observador, não tinha raiva do mato que crescia nem dos bichos que causavam danos à plantação, como a capivara. O seu prazer era ver, os outros gostavam de fazer. Queriam mudar a natureza, domesticá-la, ele preferia a ferocidade das matas, não perderia tempo tentando amansar aquela terra, via nela o animal arredio $[\ldots]$.

Lorenzo andava por toda a região e via que os agricultores queriam dominar a terra, torná-la submissa, só ele desejava sua beleza bruta. Nunca seria agricultor, descobriu isso em suas caminhadas, era um contemplativo [...]. (p. 93-94)

Cette rêverie, assez romantique, se double alors d'un arrièreplan idéologique :

LABICA, « ne sont rien d'autre qu'une anticipation [...] de la société bourgeoise et de son idéologie individualiste-libérale [...]. » ("Le marxisme entre science et utopie », Mots - Le langage du politique "Utopie... utopies ", n 35, juin 1933, p. 20).

${ }^{34}$ Jean-Louis COMOLLI, La Cécilia, Paris, Daniel C, 1976, p. 9, cit in Fernando AINSA, « Utopie, terre promise, émigration et exil », art. cit., p. 53.

${ }^{35}$ Alexandre CIORANESCU, " Utopie : cocagne et âge d'or », Diogène, n 75, p. 102.

${ }^{36}$ Les marxistes, eux, cherchent à vaincre la nature, si l'on en juge par ce qu'écrit Henri LEFEBVRE, qui se réclame du marxisme : "L'homme lutte contre la nature ; il ne doit pas rester passivement à son niveau, la contempler, ou s'immerger romantiquement en elle; il doit, au contraire, la vaincre, la dominer, par le travail, la technique, la connaissance scientifique, et c'est ainsi qu'il devient lui-même. " (Le Marxisme, 23 éd., Paris, P.U.F. "Que sais-je ? ; n 300 », p. 11). 
[...] o anarquismo não precisava ser criado, já existia na selva, a civilização era o fim desta força incontrolável.

[...] acreditava na anarquia como força primitiva, não como sistema ou ideologia civilizadora. Coitado do Rossi, estava tão iludido, precisava ver melhor as matas, ler o que elas escreviam o tempo todo, era uma mensagem que não estava nos livros. A natureza fala uma única língua, mas os livros, sempre confusos, falam muitos idiomas, até os mortos, e isso é a prova de que nunca dizem a verdade. Apenas a natureza não mente. (p. 94)

Lorenzo s'oppose donc à l'idéologue Giovanni Rossi mais aussi et surtout à Giacomo qui mange de la terre et qui n'a pas compris ce qu'est l'anarchisme :

Ele comia terra. [...] Tratava-se de um animal que sofria, mas sua principal doença era não aceitar o anarquismo da natureza, querer impor ordem ao que por princípio era caótico. Não amava o que a terra dava segundo suas regras, queria ordená-la de acordo com ideais próprios. Estava doente, todos estavam doentes. A saúde era não querer interferir em nada. Aquele mundo já conhecia a ausência de chefes, não precisava dos anarquistas para ensinar esta lição, uma lição difícil, pensou. (p. 95)

Visiblement Lorenzo se demande si l'homme est fait pour l'anarchisme. Il pense en tout cas que la nature délivre une vérité simple, débarrassée des oripeaux de l'idéologie : le principe anarchique est ce qui régit la nature, laquelle rend ainsi crédible l'anarchisme, qui serait en quelque sorte une loi naturelle. En vivant en symbiose avec la nature qui n'obéit à aucun chef, l'homme vivrait en harmonie avec le credo anarchiste. Pour Lorenzo, l'anarchisme est un sentiment naturel, une façon singulière d'être au monde : il ne devrait pas être une idéologie, c'est-à-dire un système politique inventé de toutes pièces, artificiel et donc trompeur ${ }^{37}$. L'homme anarchiste, rebelle et

\footnotetext{
${ }^{37}$ L’opinion de Lorenzo illustre les propos de Paul RICEUR sur l'idéologie : " Si l'idéologie est la fausse conscience de notre situation, nous pouvons imaginer une société sans idéologie. Mais nous ne pouvons pas imaginer une société sans utopie, car ce serait une société sans dessein. " (Liidéologie et l'utopie, éd. cit., p. 372) ; Ce même chercheur écrit ailleurs : "Ainsi, nous nous contenterons volontiers de définir l'idéologie comme un processus de distorsions et de dissimulations par lesquelles nous nous cachons à nous-mêmes par exemple notre position de classe [...]; l'idéologie est alors assimilée purement et simplement à un mensonge social ou, plus gravement, à une illusion protectrice de notre statut social, avec tous les privilèges et les injustices qu'il comporte. » (Du
} 
Le Village Anarchie Dans UN AMOR ANARQUISTA, de Miguel Sanches Neto: ...

épris plus que tout de liberté, est à l'image de cette nature indomptée, sauvage : le village Anarchie ne doit pas ressembler à la ville civilisatrice où le citadin perd son âme en éradiquant la nature autour de lui et en lui. Le Breton Jean Géléac partage l'opinion de Lorenzo : « [...] uma mata era para eles algo organizado, árvores plantadas segundo um princípio, e as matas ali cresciam livres, pensara Jean Gelèac, verdadeira lição de anarquismo. » (p. 118); il règne donc un beau désordre, une belle anarchie dans ces contrées reculées. Cette exaltation du sentiment de liberté, décuplée par les grands espaces brésiliens, conduit Lorenzo à remettre en cause la construction d'une clôture pour empêcher que le bétail détruise les récoltes : "Triste ironia, pensou Lorenzo, era uma plantação coletiva, como expulsar os animais que também queriam se apossar dela ? Uma plantação anarquista podia ter cerca ? " (p. 99). Lorenzo incarne ainsi ce que Rossi appelle le "socialismo espontâneo » ou "rudimentar » (p. 33) ; notons qu'Alain Pessin dépeint l'anarchiste comme " 'l'homme naturel' [...] qui tourne les pages du Grand Livre de la Nature $»^{38}$, comme un " homme du libre espace $»^{39}$.

Cette terre brésilienne est à plusieurs reprises associée dans le roman de Sanches Neto à la femme, ce qui est une caractéristique de l'imaginaire collectif brésilien, comme nous l'avons vu plus haut. La femme, comparée d'ailleurs à une orange douce (p. 216), se donne à l'homme comme la terre vierge s'offre au cultivateur conquérant : " Para se relacionar com o mundo, era preciso apenas deixar que as coisas passassem por seu corpo, furando-o como se fosse terra virgem, plantando uma semente [...]. » (p. 56). La terre tourne à l'obsession chez Giacomo, ce qui montre qu'elle constitue un enjeu pathétique pour ces hommes en quête de la Terre promise : «Aquilo era terra, apenas terra, mas havia algo que o atraía, que o deixava com água na boca. Ele então puxava a enxada mais rápido, excitado, amando com gula aquele solo. Era dali que viriam os alimentos, a fartura, a igualdade, o futuro, as mulheres, o conforto [...]. » (p. 91). La terre représente donc, au même titre que la femme dans une communauté presque exclusivement masculine, un enjeu capital pour que le rêve anarchiste puisse se concrétiser : « [...] a terra era tudo, o corpo de

texte à l'action - Essais d'herméneutique II, Paris, Seuil « Esprit », 1986, p. 379-380).

${ }^{38}$ Alain PESSIN, p. 83 ; voir aussi p. 80.

${ }^{39}$ Ibid., p. 84. 
Maria, a mandioca, a polenta, a laranja de todas as refeições [...], nunca deixaria de ser produtiva ; para isso, no entanto, alguém precisava adubá-la [...]. Terra. Terra. Terra. Comida. Mulher. Fruta [...]. Terra. Futuro. Carne. Leite. Terra. Tudo... » (p. 92). Dans cette fantasmagorie, la terre est érotisée par assimilation à la femme, qui porte ici un surnom révélateur; toutes deux sont ensemencées : "Queria a terra, as mãos cavavam de forma alucinada, ele pensava no corpo de Maria. Maria Boaterra. O corpo. O amor. O sonho. Mandioca. Laranja doce. Terra. A palavra tomava todos os espaços de sua imaginação. Tentava pensar en justiça. Terra. Em sexo. Terra. Em dinheiro. Terra. » (p. 92).

La Terre promise ne peut être qu'une terre d'abondance, une " terra da fartura » (98). Le mot "fartura » est maintes fois répété dans le récit : par exemple, le premier régime de noix de coco est interprété par Rossi « como um sinal de fartura ». En Italie, ce dernier fait la promotion " deste pequeno país que é nossa colônia »; le village Anarchie est par conséquent présenté comme un "lugar promissor » offrant de « prósperas colheitas » à ceux qui s'y établissent (p. 102). Grilo, l'ami de Rossi, prévoit une « colheita [...] abundante » et « um ano próspero » aux membres de la communauté (p. 85). Bref, la Cecília s'offre comme une "nova terra da fartura » (p. 34), comme une « terra da promissão » (p. 108).

Ce qui importe le plus pour les colons, c'est donc la terre et la femme : " - E o que importa ? ", demande Narcisa à Massa, qui répond, sans hésiter : "As coisas. Este tronco. Esta terra. Teu corpo. " (p. 147). Si l'homme, à l'instar de Massa, "Era parte da paisagem » (p. 146), la femme aussi doit être à la ressemblance de la nature environnante : la "fêmea selvagem ", comme Narcisa, est aux antipodes de la femme bourgeoise, soumise à son mari (p. 152). En réalité, le manque crucial et persistant de femmes dans la colonie est un problème que Rosso cherchera à résoudre par tous les moyens car les hommes, et surtout les célibataires, " sentem como nunca a falta de mulheres » (p. 50); dans une lettre, il écrit qu'il devient urgent que la Cecília accueille des femmes afin que l'esprit libertaire et anarchiste puisse s'enraciner dans la communauté : "Aguardamos todo tipo de gente, mas ficaríamos extremamente felizes se viessem também as companhias amáveis. »; et de poursuivre : "Como nossa pequena população é predominantemente masculina, sem elas a Colônia corre o risco de continuar reproduzindo todos os vícios desta 
Le Village Anarchie Dans UN AMOR ANARQUISTA, de Miguel Sanches Neto: ...

velha sociedade que queremos reformar. » (p. 50). En attendant, Rossi amène avec lui de la ville une jeune prostituée, Maria, qu'il présente aux colons comme une sympathisante anarchiste (p. 52), ce qui est un mensonge. Il commet donc une double entorse aux principes de l'anarchisme, qui combat le mensonge et la prostitution : « Lutamos contra a prostituição na política, na economia, na família [...]. » (p. 43). L'amour libre deviendra donc le point le plus important de son programme :

Rossi fez um longo discurso, sem citar nomes, cada um era dono de seu corpo, podia usá-lo da forma que quisesse, mas jamais vendêlo, o comércio era aviltante, estavam ali em vida comunitária, defendiam o amor livre, mas sem interesse econômico, pois se há desejo de vantagens, tudo se perde. A harmonia entre o indivíduo e a sociedade só poderá ser natural e espontânea quando todas as mulheres forem consideradas possíveis amantes, e todas as crianças, filhos coletivos. Só não aceitavam a prostituição, repetiu, a prostituição é uma doença do modelo familiar tradicional. (p. 160-161)

Comme la terre, la femme est collective :

- [...] Só porque são solteiros ? Os casados também têm direito. Não somos anarquistas, não temos que destruir a família ?

Nas últimas semanas, alguns homens haviam se deitado com Narcisa pelos matos da Colônia, ouvindo seu uivo de fêmea selvagem assustar passarinhos [...]. Ela tinha fome, uma fome que eles podiam matar com seus corpos acostumados apenas com o trabalho, prontos para verter a água longamente acumulada, que jorrava sobre aquela terra, coletiva como a roça em que trabalhavam. (p. 152-153)

En réactivant le mythe de Narcisse, ce personnage féminin au nom évocateur convoque l'image captivante de la beauté et de la jeunesse dans une nature paradisiaque. On retrouve ici l'association de la terre et de la femme. L'amour libre, préconisé du reste par Fourier $^{40}$, est une nécessité dans une communauté qui compte moins de

${ }^{40}$ Cf. Paul RICEUR : « On a lu Fourier comme un prophète de l'amour libre, et telle était en fait sa revendication. " (L'idéologie et l'utopie, éd. cit., p. 400). 
femmes que d'hommes, mais c'est aussi une question de principe ${ }^{41}$. Au-delà de l'idéologie anarchiste, c'est le paradis perdu de la liberté sexuelle et de "l'harmonie conforme au principe de l'attraction ${ }^{42}$ qui se profile ici. Ce thème, que nous ne traiterons pas en profondeur dans cet article, parcourt l'ensemble de l'œuvre, qui commence par un épisode d'amour libre mettant en scène le narrateur autodiégétique - Giovanni Rossi -, le Breton Jean Géléac, Adele et son mari jaloux, la jalousie étant considérée comme une maladie bourgeoise (p. 186). L'amour anarchiste vise à saper les fondements moraux de l'institution bourgeoise qu'est la famille et le mariage ; il repose sur des lois naturelles : le désir et le libre consentement ${ }^{43}$. Rossi relate son expérience, de manière enthousiaste, dans une lettre placée à la fin du récit :

Saibam que enfim estou feliz [...] com a chegada de uma moça meiga e inteligente que me trouxe o amor. Não esse amor de obrigação que está no alicerce das famílias tradicionais, mas o amor anarquista, que vem [...] com tanta lealdade [...] que estou pacificado nesta minha longa busca de uma realização que não fosse individual. Um casal e eu vivemos juntos - sem nenhum ciúme, sem desavenças - e amanhã um jovenzito francês passará a fazer parte de nossa família poliândrica. Todos nos queremos bem, e a Colônia nos admira [...] e logo passará a nos imitar. (p. 204)

Et de poursuivre : «[...] espero que o acréscimo de mais um homem em nossa família me tire os últimos sentimentos de posse,

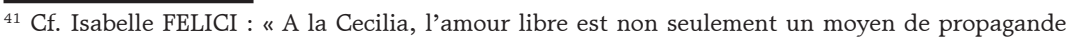
mais c'est aussi un remède à l'abstinence sexuelle à laquelle sont contraints ceux qui sont venus sans compagne. " (op. cit., p. 59-60).

42 Cf. Paul RICEUR : « Le projet de Fourier consiste donc à révolutionner les passions. La vie civilisée les a réprimées et a réduit leur nombre. [...] L'idée est que la nature a été asservie, à la fois hors de nous et en nous : notre tâche et notre possibilité consistent donc à la sauver. [...] Dans le chapitre de l'ouvrage de Desroche consacré à Fourier, cette perspective est présentée comme le mythe du jardin d'Eden, le mythe édénique de l'harmonie conforme au principe de l'attraction. La présupposition commune à Fourier et à Rousseau est que les passions sont des vertus et que la civilisation en a fait des vices. Le problème est de libérer les passions des vices, d'affranchir ceux-ci de la condamnation morale [...] afin de reconquérir les passions sous-jacentes. " (Lidéologie et l'utopie, éd. cit., p. 400).

${ }^{43}$ D'après Fourier, la femme devait pouvoir choisir librement son compagnon ; voir à ce sujet Lewis MUMFORD, História das Utopias, trad. par Isabel Donas Botto, Lisbonne, Antígona, 2007, p. 105. Georges LABICA rappelle que « le degré d'émancipation de la femme comme mesure de l'émancipation générale » était un principe cher à Fourier, qui insistait donc sur « la libération de la femme sans laquelle celle de l'homme n'est qu'un vain mot » (art. cit., p. 22, 27).
} 
Le Village Anarchie Dans UN AMOR ANARQUISTA, de Miguel Sanches Neto: ...

libertando-me completamente dessa praga que é o amor exclusivista. » (p. 204). La lettre s'achève sur une note pleine d'espoir :

Para mim, este amor sem rivalidade, sem ciúme e sem mentira é a prova final da viabilidade do socialismo, demonstrando que a Colônia pôde enfim vencer o temor das famílias e a ignorância herdade de séculos de obscurantismo. Os problemas sociais serão vencidos porque é possível amar coletivamente, sem senso de propriedade, uma mulher cujo filho será da Colônia e não de um pai.

Le « casamento anarquista » (p. 10), appelé aussi « socialista » (p. 28) ou « comunal » (p. 166) passe nécessairement par l'émancipation de la femme, comme l'écrit Rossi dans une autre lettre :

Volto a me entusiasmar com as possibilidades da Cecília, mas ainda nos fazem falta as mulheres emancipadas dos preconceitos burgueses [...]. Essas mulheres livres tirarão o poder das casadas, criando uma nova irmandade, em que o ciúme e a posse sejam definitivamente banidos, permitindo assim a vitória do clã socialista contra o egoísmo familiar. (p. 173)

Le narrateur hétérodiégétique nous apprendra cependant que « o ciúme ainda existia » (p. 130), tempérant ainsi l'enthousiasme du propagandiste de l'anarchisme. Si l'amour libre devient une question cruciale pour l'idéologue Rossi, c'est parce que le sens de la propriété et de la domination disparaîtra de lui-même lorsque l'individu aura renoncé à posséder une femme : lorsqu'il parviendra à partager une femme, c'est-à-dire l'être auquel il tient le plus au monde, avec un autre homme, alors le sens de la communauté et l'anarchisme l'emporteront. C'est ce qui ressort de cette autre lettre :

[...] o amor livre foi enfim posto em prática, e logo vocês receberão mais notícias desta grande experiência. Estamos enfim mudando os possessivos, também no amor não existe mais $o$ meu e sim $o$ nosso, e com isso nos tornamos efetivamente anarquistas - o anarquista que defende sua mulher é tão reacionário, tão feroz e tão implacável quanto o pior dos capitalistas defendendo seus milhões. (p. 192)

L'amour libre et non libertin, car il ne s'agit pas de cacher 
quelque chose ou de tromper quelqu'un, constitue par conséquent la quintessence de l'utopie libertaire de Rossi : voilà pourquoi l'amour libre est présenté d'entrée de jeu comme une question éthique ${ }^{44}$, comme un « ato político consciente » (p. 72). Pour mener l'expérience jusqu'à son terme, il accueillera les filles d'Adele comme ses propres enfants car « era tudo uma questão ética » (p. 245) : «Um homem decente, você sabia que as filhas eram de Gelèac e de Aníbal, não eram suas, mas disse nossas filhas. » (p. 244), se dit en elle-même Adele. L'utopie communautaire s'étend par conséquent jusqu'aux femmes et aux enfants, qui appartiennent à la communauté, l'amour libre étant présenté de manière presque simpliste par Rossi, devenu ici personnage de roman, comme l'achèvement, le véritable terme de l'anarchisme, autrement dit comme le " centro da grande revolução " (p. 221). Notons au passage que l'association amour/révolution est souvent présente dans le discours révolutionnaire, sans doute parce que l'amour est l'expression de l'élan vital, d'une énergie transformatrice, qui est à l'œuvre dans le processus révolutionnaire et chez les femmes lorsqu'elles découvrent l'amour « anarchiste » à la Cecília (p. 206).

C'est donc sur la question de l'amour libre, qui a donné le titre à son livre, que Miguel Sanches Neto a focalisé son récit car il s'agit là de l'aspect le plus romanesque de la vie de Giovanni Rossi. L'auteur brésilien s'inspire en effet du bilan intitulé Cecilia, comunità anarchica sperimentale, que Rossi fait paraître en 1893, alors qu'il songe à quitter la colonie : la deuxième partie de cet écrit s'intitule Un episodio d'amore nella colonia Cecilia ; ce texte, qui contient d'ailleurs un questionnaire sur l'amour libre établi par Rossi ${ }^{45}$, auquel fait écho le début du roman de Sanches Neto - « Não era um homem que estava fazendo estas perguntas, mas um profissional. » (p. 11) - est conçu, d'après Isabelle Felici, " comme un instrument de propagande contre cet ennemi séculaire qu'est l'institution familiale $»^{46}$, " na qual o homem faz as vezes da figura odiosa do patrão » (p. 29), comme le déclare Rossi dans Um Amor Anarquista, comparant ainsi le mari possessif à un odieux patron.

${ }^{44}$ Selon Alain PESSIN, on peut définir « l'anarchisme d'abord comme une éthique » (op. cit., p. 114 ; voir aussi p. 215).

45 Voir à ce propos Isabelle FELICI, op. cit., p. 59 ; plusieurs pages du roman qui nous requiert sont consacrées à ce questionnaire (p. 200-203).

${ }^{46}$ Ibid. 
Le Village Anarchie Dans UN AMOR ANARQUISTA, de Miguel Sanches Neto: ...

Comme dans toute utopie, Rossi voudra créer un homme nouveau ; il s'agira ici, bien entendu, de l'homo novus anarchiste qui est comparé à une plante poussant au milieu de la mauvaise herbe : «Esta planta, em menor quantidade, sempre nascerá, sempre frutificará. » (p. 28). Ce mythe de l'homme nouveau va de pair avec l'idéal du recommencement; naturellement, le Nouveau Monde était l'endroit le mieux indiqué pour renaître et tout recommencer. Sur cet idéal du recommencement, à l'œuvre dans l'Apocalypse, dernier livre de la Bible, qui annonce un retour à l'âge d'or, une nouvelle création, Deleuze écrit :

La seconde origine est donc plus essentielle que la première, parce qu'elle nous donne la loi de la série, la loi de la répétition dont la première nous donnait seulement les moments. Mais ce thème, plus encore que dans nos rêveries, se manifeste dans toutes les mythologies. Il est bien connu comme mythe du déluge. [...] L’idée d'une seconde origine donne tout son sens à l'île déserte, survivance de l'île sainte dans un monde qui tarde à recommencer. Il y a dans l'idéal du recommencement quelque chose qui précède le commencement lui-même, qui le reprend pour l'approfondir et le reculer dans le temps. Lî̂le déserte est la matière de cet immémorial ou ce plus profond. ${ }^{47}$

L'expérience de la Cecília est d'emblée placée sous le signe du renouveau, à telle enseigne que les colons " se sentiam primitivos " (p. 36); l'espace vierge à conquérir exacerbe sans doute ce sentiment de recommencement : " o que nos move é este tênue sentimento de juventude » (p. 28). Ainsi, ce projet utopique réactive le mythe de la jeunesse éternelle car « sempre haverá gente amando pela primeira vez » (p. 28) et, comme chacun sait, " o mundo pertence aos jovens » (p. 118). Dès le départ, les premiers colons, ou plutôt, les pionniers, ont le sentiment de réaliser un rêve de jeunesse et d'être en avance sur leur temps dans un " monde qui tarde à recommencer ", pour reprendre le mot de Deleuze : « [...] estávamos dentro de nosso sonho juvenil. [...] aqui o socialismo anárquico já é realidade. // passamos a noite neste território livre em que hoje, novamente reunido o grupo de pioneiros, cinco homens e uma mulher vivem livremente,

${ }^{47}$ Gilles DELEUZE, "Causes et raisons des îles désertes ", in Lîle déserte et autres textes - Textes et entretiens (1953-1974), Paris, Ed. de Minuit « Paradoxe », 2002, p. 17. 
algumas décadas à frente do resto da humanidade. » (p. 20). Dans cette citation, tout exprime la nouveauté : les mots « novamente » et "pioneiros ", le passage de la nuit au jour nouveau, qui peut être pris dans un sens métaphorique, ainsi que le don de l'anticipation suggéré par l'expression « algumas décadas à frente do resto da humanidade ». Ainsi, un « novo homem », une « nova sociedade [...] começava ali com eles » (p. 183).

Par conséquent, Rossi nous renvoie une image édénique de l'enfance du monde, qu'il restaure sur cette terre brésilienne qui lui donne une seconde jeunesse : « aquele contato com a terra tinha nos devolvido aos anos matinais " (p. 19). Sur cette " nova e maravilhosa terra » (p. 70) où les colons se sentent renaître, nous avons alors affaire à une nouvelle création car un " novo tempo » (p. 116) commence, donnant naissance à des " homens novos » (p. 43), à des " pessoas novas » (p. 85) qui, bien sûr, se destinent à " uma vida nova, num lugar promissor » (p. 102). D'ailleurs, Rossi pense déjà au premier enfant, symbole de renouveau, qui naîtra dans la colonie : « [...] logo viria a criança, a primeira a nascer na Cecília, tinham que arranjar um nome adequado para ela, o nome das coisas era importante, uma escolha errada e tudo poderia estar perdido [...]. » (p. 51) ; en bon libertaire, il voudrait lui donner un nom révolutionnaire, Libero (p. 82). Un monde nouveau, où chaque chose doit trouver un nom pour exister réellement, comme dans la Genèse, occupe les pensées du Dr. Rossi. Il est à remarquer que dans une cité idéale, la monotonie, la routine n'ont pas leur place car tout est nouveauté dans le village Anarchie, qui doit trancher avec l'espace urbain normatif, c'est-à-dire avec la ville bourgeoise. C'est pourquoi la jeune prostituée Maria, en quête d'expériences sexuelles sans cesse renouvelées, appréciera la « nova mudança » (p. 54) que lui procurera la vie à la Cecília, où elle effectue un retour à l'enfance; en ville, en revanche, " a novidade era infinitamente menor do que a repetição » (p. 56), constate-t-elle. Le réenchantement du monde passe donc par la découverte incessante de la nouveauté, qui est le véritable ressort de la vie et de la création.

A ce propos, on assiste en quelque sorte à une nouvelle création du monde ${ }^{48}$, ce que propose toute utopie, comme le montre l'auteur

${ }^{48}$ Cf. idem : "Tout ceci [l'idéal du recommencement] suppose évidemment que la formation du monde soit à deux temps, à deux étages, naissance et renaissance, que le second soit aussi nécessaire et essentiel que le premier, donc que le premier soit nécessairement compromis, né pour 
Le Village Anarchie Dans UN AMOR ANARQUISTA, de Miguel Sanches Neto: ...

avec justesse dans une des premières lettres de Rossi : « Desde que os pioneiros se estabeleceram, nossos dias têm sido de trabalho bíblico, estamos criando um mundo do nada. [...] aqui nosso projeto é deixar a teoria em nome da prática [...]. [...] Estamos confiantes no futuro da comunidade, que já principiou socialista [...]. » (p. 32 ; c'est nous qui soulignons). Ces « imigrantes comuns» (p. 32) sont donc à l'origine d'un nouvel âge du monde ; il va sans dire que l'utopie, religieuse notamment, nourrit l'attente d'un retour au bonheur des origines. A ce propos, l'utopie est aussi une quête du bonheur, ici et maintenant $^{49}$ (p. 42).

Par ailleurs, l'attente d'un nouvel âge d'or va de pair avec la foi dans l'avenir : il s'agit bien de foi, comme en religion, ce dont témoigne Adele pour qui le travail harassant à la Cecília sert « apenas para acreditar » (p. 26). Les spécialistes ont déjà abondamment montré que la pensée utopique est tendue vers le futur. En effet, d'après Alexandre Cioranescu,

L'utopiste croit que l'avenir peut être le produit d'un mythe projeté vers l'avant, comme l'âge d'or est un mythe projeté vers le passé [...]. [...] il parie que ces combinaisons mentales [les spéculations utopiques] auront des résultats heureux et bienfaisants, parce qu'il construit avec les matériaux qu'il retrouve dans ses nostalgies, déduisant de l'image d'une enfance heureuse l'hypothèse d'une chance de bonheur. ${ }^{50}$

Fernando Ainsa, quant à lui, rappelle que le futur se trouve à la base de la pensée utopique qui projette l'utopiste dans un «temps désirée " ${ }^{51}$; ailleurs, il écrit : "Avec l'utopie, on mise sur le futur à partir d'un territoire nouveau, riche en puissance. $»^{52}$. Le récit utopique situe par conséquent l'action dans un futur "parfait », ce qui conduit Piovezani Filho à parler de « mythification du futur ",

une reprise et déjà re-nié dans une catastrophe. " (ibid., p. 16 ; voir aussi Fernando AINSA, " La découverte de l'autre et l'invention de l'utopie », art. cit., p. 53).

${ }^{49} \mathrm{Cf}$. Alexandre CIORANESCU : «Enfin, il faut aussi tenir compte du fait que l'utopie ne s'intéresse qu'au destin de l'homme ici-bas et à son bien-être matériel, sans se poser le problème de son salut, sans lui offrir l'espoir ou l'illusion d'une transcendance métaphysique [...]. » (art. cit., p. 95).

${ }^{50}$ Ibid., p. 91.

${ }^{51}$ Fernando AI NSA, «Utopie, terre promise, émigration et exil », art. cit., p. 64 ; voir aussi p. 61, n. 19 et 20

52 Fernando AINSA, "La découverte de l'autre et l'invention de l'utopie », art. cit., p. 53. 
laquelle caractérise, selon lui, le discours politique et religieux, qui vise à faire des adeptes :

Se uma das mais constantes inquietações humanas [...] é justamente a impossibilidade de prever e, por extensão, controlar o que acontecerá no futuro, e se se tem, por meio de um construto discursivo, uma garantia de assegurar o futuro, na instância político-econômico-social, não há como não se sentir tentado diante de tal garantia. Por isso, e também pelo facto de considerar a quase permanente insatisfação dos homens para com o seu presente [...], a abertura do futuro permite vislumbrar um eu melhor no devir, campos discursivos como o político e o religioso apresentam como um de seus traços mais indeléveis justamente a projeção para o futuro, tempo em que « tudo será melhor ».53

Miguel Sanches Neto reproduit en pointillé ce futur parfait dans le discours utopique qui prévaut au village Anarchie, lequel est à l'avant-garde de l'humanité : ses habitants, en effet, " vivem [...] algumas décadas à frente da humanidade » (p. 20). L'anarchisme promet, d'après son propagandiste, un « belo futuro » (p. 102) à ceux qui vivront selon ses principes; en attendant, il faut avoir foi dans l'avenir ${ }^{54}$ : «Estamos confiantes no futuro da comunidade [...]. » (p. 32), écrit Rossi dans l'une de ses premières lettres de propagande. Le narrateur hétérodiégétique met aussi l'accent sur cette foi dans l'avenir tout en la relativisant par le biais d'une référence négative à la réalité, qui est tout autre : " $O$ feijão ainda não existia, mas o futuro era tão perto, tão imediato e tão real que Giacomo sentia o sabor do feijão no cheiro daquela terra. » (p. 91) ; le futur semble donc à l'utopiste plus réel, plus immédiat, d'où le recours au futur proche (" vai surgir o milho ", p. 143), et surtout bien plus exaltant que le présent, source de frustration. Même lorsqu'il songera à quitter la Cecília, Rossi écrira : « [...] estou vivendo o futuro. » (p. 222). L'avenir est donc l'idéal auquel il ne renonce pas car l'utopiste est toujours

\footnotetext{
${ }^{53}$ Carlos Félix PIOVEZANI FILHO, «Velhas noções, em novos tempos : estratégias lingüísticas do discurso político ", Letras \& Letras [Université Fédérale d’Uberlândia], vol. 22, n 1, janv.juin 2006, p. 94-95, version électronique in http://www.letraseletras.ileel.ufu.br/viewissue. php?id=10, page consultée le 27 juillet 2007.

${ }^{54}$ L'Avvenire était un journal anarchiste fondé à São Paulo en 1883 ; voir à ce sujet Regina JOMINI-MAZONI, Ecoles anarchistes au Brésil (1889-1920), Lyon / Lausanne, Atelier de Création Libertaire « Commune Mémoire » / Ed. Noir, 1999, p. 16.
} 
Le Village Anarchie Dans UN AMOR ANARQUISTA, de Miguel Sanches Neto: ...

tourné vers le futur, comme le montre le narrateur hétérodiégétique qui parle de ses « olhos voltados para o sonho, numa imagem interior que era mais forte do que a realidade, pois a realidade para ele não existia, a realidade era falsa, tão vivos os seus ideais. » (p. 230) ; la force du rêve chez l'utopiste, qui est toujours mû par la «nostalgia do futuro » (p. 21), l'emporte donc sur la réalité desséchante qui l'entoure : l'utopie est réalisable puisqu'elle existe déjà à l'état de rêve, le rêve étant en quelque sorte sa préfiguration.

Miguel Sanches n'a donc pas omis d'introduire, dans le discours utopique de Rossi, le futur prophétique, dont il atténuera la portéee: "Quando nossa população crescer, haverá ócio para as artes, para a leitura, para o namoro ou apenas para contemplar os entardeceres, que não nos doerão tanto, pois a solidão estará afastada e o pôr-do-sol poderá ser apenas poesia. » (p. 49-50). Les verbes employés au futur sont cependant très peu diversifiés et d'un usage tout à fait courant : haverá, estará, poderá, comme dans la citation ci-dessus, ou bien alimentará (p. 143), plantaremos (p. 146) : ces verbes traduisent une réalité assez terre-à-terre, le rêve utopique étant vidé de sa substance. Tout se passe comme si l'on assistait à un détournement du discours utopique, le conditionnel remplaçant volontiers le futur lorsque le narrateur hétérodiégétique raconte l'histoire de la Cecília, comme dans ce passage : « [...] logo haveria a primeira colheita. [...]. [...] um dia a fartura seria tanta que não haveria razão para enganar os outros. $/ /[\ldots]$ mas dinheiro eles só teriam dentro de alguns meses. » (p. 42). En reproduisant, au conditionnel, le discours de Rossi, le narrateur hétérodiégétique minore la portée exaltante du discours utopique qui projette ainsi le lecteur dans un futur immédiat tout à fait terne, le conditionnel renvoyant même à un avenir compromis. Naturellement, ce choix en ce qui concerne les temps verbaux s'explique car l'auteur, rappelons-le, n'a pas écrit un récit utopique mais un récit sur une utopie qui s'est soldée par un échec cuisant ; de plus, il convient de gommer, par le biais du conditionnel, le sentiment de désillusion qui se dégage du roman car Miguel Sanches Neto veut malgré tout rendre hommage à ces pionniers d'un genre nouveau, qui ont fondé la Cecília, et faire vibrer le lecteur. 


\section{L'ECHEC DE LA CECILIA : L'HOMME ET LE SYSTEME MIS EN CAUSE}

Le but du Dr. Rossi était de "fundar [um] pequeno país anarquista de duzentos hectares » (p. 222), à un moment où l'Etat brésilien cédait gratuitement des terres aux étrangers, pour « montrer [...] que le Brésil offrait des conditions d'immigration avantageuses par rapport à d'autres pays du continent comme l'Argentine ou les Etats-Unis. $~^{55}$; si Rossi préfère finalement le Brésil à l'Uruguay, c'est pour des raisons matérielles : «[...] embora inicialmente tivéssemos vontade de ir para o Uruguai, encontramos mais facilidades de imigração para o Brasil, cujo governo nos deu transporte gratuito e nos prometeu terras a prazo. » (p. 17) ; Rossi s'attire les faveurs du gouverneur (p. 69). Là encore, ce qu'écrit Miguel Sanches Neto correspond bien à la réalité, si l'on en croit Regina Jomini-Mazoni :

Il semble qu'un projet d'immigration dans la région du Paraná n'a pas pu se réaliser. Les familles des colons, trompés par les agents chargés de vendre les terrains, ont dû être rapatriés à la charge du gouvernement impérial. La répercussion internationale de cette affaire paraît ne pas être étrangère à la cession de terres en faveur de Rossi. ${ }^{56}$

Rossi, qui rêve d'une " grande pátria anarquista » (p. 49), quitte donc sa «triste pátria », c'est-à-dire cette «Itália católica » (p. 16), pour fonder une « colônia social » (p. 20), « longe da opressão dos patrões » (p. 70) ; c'est donc non loin de la ville de Palmeira qu'il œuvre à la " vitória do socialismo » (p. 70), raison pour laquelle la colonie Cecília reçoit le nom, très explicite, de «Vila Anarquia » (p. 22) dans le roman de Miguel Sanches Neto. Le terme de «village » se justifie pleinement car il traduit une volonté de rupture avec la ville, qui symbolise l'ordre bourgeois et l'exploitation des ouvriers ; pour certains anarchistes, la ville était le « lieu du Mal», comme le souligne Alain Pessin ${ }^{57}$, qui précise que Bakounine privilégiait la propagande en milieu paysan, rêvant d'une " guerre paysanne à allure anarchi-

\footnotetext{
${ }^{55}$ Ibid., p. 14.

${ }^{56}$ Ibid., p. 14-15; le roman de Miguel Sanches Neto fait écho à cette regrettable affaire (p. 70).

${ }^{57}$ Alain PESSIN, op. cit., p. 77.
} 
Le Village Anarchie Dans UN AMOR ANARQUISTA, de Miguel Sanches Neto: ...

que ${ }^{58}$. Toutefois, le développement industriel provoque la fixation des ouvriers dans les villes et surtout dans les faubourgs populaires. L'anarchiste-propagandiste errant, formule que nous empruntons à Alain Pessin, est donc contraint de s'intéresser au milieu urbain où se concentrent les masses laborieuses, phénomène accentué par l'exode rural qui entraîne la conversion des paysans en ouvriers. La ville est capable d'effervescence et d'agitation sociale, devenant ainsi un champ d'expérimentation et de bataille privilégié pour les anarchistes qui s'y établissent ${ }^{59}$ : dans les faubourgs, dès les années 1880 , se constituent des territoires anarchistes, comme le note Alain Pessin, ce qui " n'implique en aucune manière un mode de vie spécifique ", c'est-à-dire la formation d'une "contre-société " ${ }^{60}$. Vu qu'ils aiment plus que tout la « vie au grand air, la liberté de diriger [leurs] pas où bon [leur] semble » et qu'ils ont habituellement pour " laboratoire le monde entier ${ }^{61}$, ils se vivent comme des étrangers dans la ville, comme des individus en rupture avec leur environnement immédiat ${ }^{62}$; dans la ville bourgeoise, ils sont très vite perçus comme de mauvais sujets $^{63}$. La " ville hostile ", " c'est-à-dire la ville prolétarienne, celle qui disqualifie les valeurs classiques de l'anarchisme ${ }^{64}$ ne sera plus un lieu que les anarchistes, "méconnaissant lois et frontières " ${ }^{65}$, chercheront à fuir ; c'est alors qu'on assistera aux « Rencontres promises et inévitables des libertaires et des villes pour l'inauguration des temps nouveaux ${ }^{66}$. Raymond Ruyer, quant à lui, fait le commentaire suivant à propos du rapport qu'entretient l'utopiste avec la cité idéale :

L'habitude, si constante dans la vie urbaine - et si agréable - d'habiter assez loin du lieu de son travail, dans une rue quelconque où travaillent d'autres personnes qui habitent ailleurs, est une habitude typiquement anti-utopienne. L'utopie veut toujours faire

\footnotetext{
${ }^{58}$ Ibid., p. 77.

59 Ibid., p. 84.

${ }^{60}$ Ibid, p. 49.

${ }^{61}$ Ibid., p. 79, 80 .

62 Ibid., p. 83, 84.

${ }^{63}$ Ibid., p. 78 .

${ }^{64}$ Ibid., p. 84.

${ }^{65}$ Ibid., p. 80

${ }^{66}$ Ibid., p. 85 .
} 
coïncider les frontières et aussi les normativités. [...] Les utopistes ont la notion - peut-être juste - que, dans l'idéal, tout doit se rejoindre harmonieusement et qu'il n'y a plus ni antinomie ni dissociation. ${ }^{67}$

On comprend mieux pourquoi Rossi a voulu dès le départ fonder une communauté agricole : "Que venham os agricultores desejosos de participar desta nova terra da fartura [...] ", écrit-il dans une lettre (p. 34) ; pour Maria, la jeune prostituée de la ville, "Aqueles homens barbudos e de roupas remendadas não faziam parte da cidade » (p. 57). Pour échapper à l'exploitation dont ils sont victimes, des ouvriers des villes, ayant participé à des luttes sociales, se joignent aux agriculteurs de la colonie, ce qui bouscule les habitudes culturelles qui régnaient à la Cecília : ces « recém-chegados [...] iriam comprometer a vida na Cecília, ameaçando pequenos confortos "; il s'agit de " novos imigrantes, quase todos da cidade, com experiência apenas na luta política » (p. 104). C’est ainsi que la Cecília « quase não era mais agrícola » (p. 61) ; elle se tournera même vers une " atividade industrial, a fábrica de barris » (p. 183). Au lieu de cultiver la terre, ces « empregados urbanos ", qui avaient connu « a humilhação da miséria e da subordinação » (p. 85), construiront donc des maisonnettes, " dando forma à Vila Anarquia » (p. 105).

Le Dr. Rossi veut instaurer à la Cecília le « socialismo anárquico » (p. 20) et opte, en tant qu'anarchiste, pour un système communautaire et libertaire, différent, donc, du système foncièrement collectiviste prôné par les communistes qui étaient favorables à un Etat bureaucratique; le communautarisme tranche avec l'individualisme bourgeois ${ }^{68}$ et l'anonymat qui règnent en ville. Rossi cherche donc à promouvoir un " novo modelo social » (p. 34), contrepoint de celui qu'offre la ville. Ainsi, au village Anarchie, tous sont « convencidos da urgência de acabar com os patrões » (p. 86) ; il faut aussi en finir avec les prêtres : « [...] urgia doutrinar as crianças, para que crescessem [...] livres das mentiras propagadas por padres e patrões, essas duas pragas. " (p. 135). Rossi se chargera lui-même de l'éducation des enfants de la Cecília (p. 169) ; la colonie compte d'ailleurs une

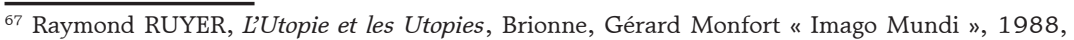
p. 105.

${ }^{68}$ Cf. Alix LARGE : « [...] une des caractéristiques profondes de l'anarchisme est d'être traversé par cette incessante tension entre l'individu et le collectif. » (op. cit., p. 22). 
Le Village Anarchie Dans UN AMOR ANARQUISTA, de Miguel Sanches Neto: ...

école ${ }^{69}$ mais aussi une bibliothèque (p. 103) où le « livro socialista » (p. 49) occupe une place privilégiée, propagande oblige. Les anarchistes des villes comme des campagnes essayaient toujours de fonder une école (p. 97), où enseignaient généralement des militants ${ }^{70}$, pour arracher "l'enfant au curé et au gouvernement " ${ }^{71}$, lit-on dans l'essai que Regina Jomini-Mazoni consacre aux écoles anarchistes au Brésil ; les anarchistes recouraient d'ailleurs à des méthodes innovantes appréciées des autorités brésiliennes ${ }^{72}$ car elles pouvaient " ajudar na melhoria da instrução da província » (p. 69). L'école, comme la presse $^{73}$, est évidemment un puissant relais de l'idéologie, raison pour laquelle Rossi inculque aux enfants, pendant ses cours, " os princípios do socialismo e do anarquismo » (p. 166). Il fallait, enfin, détruire l'ordre familial bourgeois et, par conséquent, « destruir a prisão da fidelidade conjugal » (p. 135); la famille traditionnelle constituait, aux yeux de Rossi, une entrave à la liberté, qui sera définitivement conquise lorsque l'amour libre deviendra une pratique courante dans la « colônia experimental » (p. 83) mais il s'agit là d'un objectif difficile à atteindre : « [...] mas Rossi teve a certeza de que o grupo dificilmente conseguiria chegar à prática do amor livre, única forma de levar adiante as idéias do socialismo ; a família sanguínea era um entrave para a conquista da liberdade coletiva. » (p. 82); comme tout utopiste, le Dr. Rossi doute de la capacité du groupe à passer de la théorie à la pratique. Par ailleurs, notons qu'il ne faut pas confondre les femmes libérées de la Cecília avec les «mulheres livres na cidade » (p. 40), qui sont des prostituées et non pas des militantes (p. 72). Naturellement, dans cette communauté libertaire, « a liberdade figurava como o maior bem » (p. 240) : l'homme ne s'accomplit pleinement

\footnotetext{
${ }^{69}$ Le fouriérisme prônait une éducation communautaire, sans contraintes, sans distinction de classe ou de sexe ; voir à ce propos Charles FOURIER, A Infância Emancipada, trad. par Luís Leitão, Lisbonne, Antígona, 2007.

70 Voir à ce sujet Regina JOMINI-MAZONI, op. cit., p. 77.

${ }^{71}$ Ibid., p. 28.

72 Cf. idem : «Durant les vingt dernières années du régime impérial, les députés [...] discutent de la nécessité d'améliorer l'éducation au Brésil. Selon les principes libéraux chers à certains politiciens de l'époque, l'ouverture du champ éducationnel à de nouvelles tendances pédagogiques est la voie à suivre pour arriver à la prospérité américaine et européenne. [...] Il est possible d'affirmer que la création des écoles anarchistes s'inscrit dans le contexte de cette idée libéralisatrice des élites par rapport à l'éducation. La proclamation de la République vient donner encore plus de poids à ces positions car elles étaient défendues par les membres et sympathisants du Parti Républicain [...]. Cependant, ces convictions libérales des gouvernants ne les ont pas empêchés de réprimer violemment le mouvement et les écoles anarchistes [...]. » (ibid., p. 21 ; voir aussi p. 17).

${ }^{73}$ Sur la presse anarchiste de cette époque, voir Regina JOMINI-MAZONI, op. cit., p. 16. 
que dans la liberté, qui est le principe anarchiste suprême.

Dans le système communautaire mis en place par Rossi, le travail n'est pas obligatoire (p. 137), l'anarchiste revendiquant un "droit à la paresse et à la vie " $^{74}$, et la production, qui ne peut être que collective (p. 176), n'est pas orientée vers le profit (p. 69); de plus, les membres de la communauté doivent être unis par un idéal d'égalité (p. 176). Tout est donc collectif : la terre ${ }^{75}$ (p. 153), la liberté (p. 82), qui ne doit pas être l'apanage des riches et des puissants ; la " vida coletiva » (p. 173) implique que l'on mange dans une « cozinha coletiva » (p. 74, 117), que l'argent serve à alimenter une " caixa coletiva » (p. 34) et que les décisions soient prises collectivement, par le biais d'un vote le cas échéant (p. 40-41), car au village Anarchie il n'y a pas de chef (p. 169). On vit aussi sous le même toit, d'où la construction d'un " alojamento dos solteiros » (p. 52), sans cloisons (p. 130) : toutefois, le communautarisme ne sera pas complet puisque les couples mariés voudront loger dans une autre maison (p. 72), en attendant la construction de maisonnettes (p. 105) : en effet, d'après Regina Jomini-Mazoni, le « projet initial de vivre tous ensemble dans la maison commune est refusé par les mères de famille ${ }^{76}$.

Il est donc difficile de renoncer au mode de vie bourgeois et citadin, qui continue d'exercer un certain attrait sur les colons, lesquels quittent la colonie les uns après les autres, comme Zerla : « [...] era anarquista, mas queria conviver com gente instruída, queria uma vida com mais conforto, para que esta privação toda ? » (p. 225). Rossi non plus n'est pas insensible au confort bourgeois (p. 73) dans lequel s'est installé le Dr. Grillo, son meilleur soutien au Brésil :

O conforto daquela casa o devolvia, por contraste, à sua cabana. Se tivessem fartura lá, tudo seria mais fácil, o socialismo anárquico poderia se desenvolver, não precisariam passar por privações que não se referiam diretamente à ideologia, mas à pobreza.

$[\ldots$

....]

[...] dormiu um sono longo, pensando que talvez ele também merecesse o conforto de um lar, móveis de qualidade e tempo para

\footnotetext{
${ }^{74}$ Alain PESSIN, op. cit., p. 52.

${ }^{75}$ Cf. Alexandre CIORANESCU : « [...] la suppression de la propriété [...] préoccupe [...] de façon presque constante les utopistes en général. » (art. cit., p. 92).

${ }^{76}$ Regina JOMINI-MAZONI, op. cit., p. 15.
} 
Le Village Anarchie Dans UN AMOR ANARQUISTA, de Miguel Sanches Neto: ...

livros e hábitos de higiene, praticamente banidos de sua rotina de agricultor. (p. 44-45)

La dure vie des champs tournera vite au cauchemar, si bien que les colons sont de plus en plus attirés par les grandes villes, comme São Paulo, où la vie est intense et "civilisée »: Giacomo « iria embora, para uma cidade onde pudesse trabalhar e conviver com gente esclarecida, estava cansado de tanta ignorância. [...] Em São Paulo estaria novamente na civilização, lá voltaria a ser gente. » (p. 105) ; quant à Massa, qui rêve d'avoir une chambre en ville (p. 158), « Não suportaria mais andar pelas matas, queria uma cidade cheia de ruas. " (p. 159), car « queria viver sozinho agora, um dia voltaria a ser anarquista, mas agora era apenas um homem » (p. 158). Aníbal, lui, sombre dans l'alcoolisme (p. 241) tout en rêvant d'un mode de vie petit-bourgeois : il veut en effet devenir commerçant et vivre dans une maison avec des rideaux aux fenêtres et des nappes brodées sur les tables (p. 229). C'est finalement le modèle citadin qui l'emporte, la ville en expansion exerçant une grande fascination sur l'homme du XIX ${ }^{\mathrm{e}}$ siècle, ce qui ressort de la littérature de cette époque : «- Deve existir lugar para nós na capital. » (p. 109), pense un colon sur le point de quitter la Cecília ; les grands centres urbains, " onde todos tentavam recomeçar a vida longe das atividades rurais » (p. 163) attirent donc les anarchistes et les paysans, ce qui alimentera le thème de l'exode rural dans la littérature brésilienne : la prégnance du mode de vie urbain commence donc à se faire sentir au XIX ${ }^{\mathrm{e}}$ siècle bien que la ville, volontiers assimilée à Babylone, soit très vite perçue comme un problème. Quant au Dr. Rossi, il finira par mener une vie bien rangée en tant que " professor de Agronomia e Veterinária da Escola de Agricultura do Rio Grande do Sul » (p. 240), renouant avec le mode de vie bourgeois. L'anarchisme ne représente plus pour lui qu'un idéal à usage personnel : dans la dernière lettre figurant dans le roman, il confie qu'il continue « acreditando, mais para uso pessoal, no anarquismo » (p. 240).

Un travail harassant qui épuise les hommes, des dettes chez les commerçants qui s'accumulent (p. 74) ${ }^{77}$, ainsi qu'une campagne de diffamation (p. 191-192) et une vague de répression ${ }^{78}$ (p. 70, 109,

\footnotetext{
${ }^{7}$ Ibid., p. 15.

${ }^{78}$ Ibid.

458 Olhar de professor, Ponta Grossa, 11(2): 431-473, 2008.
Disponível em <http://www.uepg.br/olhardeprofessor>
} 
246) qui s'amplifient lasseront les colons, lesquels nourrissent désormais un rêve très prosaïque : " passaram a sonhar com a partida " (p. 226) ; tous veulent en effet « abandonar a vida de privações » (p. 211). La Cecília leur laissera un souvenir saumâtre : " Era isso que ganhara - a desilusão, a mesma fome e o remorso do erro. Tinha sido um equívoquo, ela perdera tudo, até as recordações. A raiva mata as recordações, transforma tudo em ódio, não há lugar para memórias. » (p. 109). Ainsi, « O sol ainda sorria, mas agora ironicamente » (p. 118) : le mythe de la cité radieuse, baignée d'un soleil éclatant, est maintenant pris à rebours.

En réalité, la Cecília a toujours été dépendante du monde extérieur. Les colons étaient en effet contraints de travailler pour l'Etat (p. $96,126,150)$, la construction de routes rapportant quelque argent à la communauté (p. 107). Cette dépendance vis-à-vis de l'Etat et des centres bourgeois, qui représentent un « sistema corrupto » (p. 46), a de quoi compromettre la réussite du projet communautaire de Rossi, lequel voulait justement combattre les « vícios desta sociedade velha » (p. 50), d'où l'importance à ses yeux du modèle agraire, propice à la vie en communauté (p. 121-122).

L'heure du bilan a sonné. Rossi est obligé d'admettre que les principes anarchistes n’ont guère été respectés à la Cecília, où prévalent « o descaso pelo outro, o desrespeito à liberdade, a produção individualizada » (p. 112); en réalite, la colonie n’a pas dépassé le stade de coopérative agricole " sem conselho administrativo » (p. 132), ce qui implique sur le plan organisationnel des « reuniões constantes » (p. 210)79. L'échec de Rossi s'explique, entre autres choses, par le fait que les membres de la Cecília n'étaient pas tous de véritables anarchistes, comme le note Isabelle Felici ${ }^{80}$; cette expérience coïncide en effet avec la première grande vague d'émigration vers le Brésil ${ }^{81}$, la majorité des immigrants à ce moment-là étant d'origine italienne ${ }^{82}$. Parmi ceux qui s'installent au village Anarchie, il faut donc distinguer

\footnotetext{
${ }_{79}$ Cf. Regina JOMINI-MAZONI : « D'autres sont déçus du mode de vie et d'organisation de la colonie. La mise en commun des ressources financières n'a pas plu à tout le monde. Les décisions, prises par consensus dans des [sic] nombreuses réunions, en lassent quelques-uns. " (op. cit., p. 15). ${ }^{80}$ Isabelle FELICI, op. cit., p. 78.

${ }^{81}$ Claudi R. CRÒS se réfère à " l'irruption de l'immigration massive des Européens dès 1883 et surtout dès 1890 " (La civilisation afro-brésilienne, Paris, P.U.F. " Que sais-je ? ; n 3170 ", 1997, p. 99).

${ }^{82}$ Voir à ce propos Regina JOMINI-MAZONI, op. cit., p. 8-13 ; voir aussi Fernando AINSA, « Utopie, terre promise, émigration et exil », art. cit., p. 58-59.
} 
Le Village Anarchie Dans UN AMOR ANARQUISTA, de Miguel Sanches Neto: ...

les anarchistes sincères des immigrants plus ou moins opportunistes, qui ne sont que des "fugitivos da fome " ou des « desesperados do destino » (p. 137) : certains reviendront même à la Cecília en raison des « frustrações que a vida urbana sempre traz a quem é de forma profunda apenas agricultor » (p. 123). Ainsi, la Cecília pâtira d'une mauvaise sélection de ses membres (p. 137) et « da propaganda negativa feita pelos dissidentes » (p. 13) ; ceux qui quitteront la colonie, jetant le discrédit sur elle (p. 138, 150), seront considérés comme des « desertores » et surtout comme les «piores detratores dos anarquistas » (p. 129). Cette arrivée massive d'immigrants dans la colonie est comparée par Lorenzo à une invasion de criquets, l'une des sept plaies d'Egypte dans la Bible : «E não queria estar ali para ver o fim daquela região, cada dia mais invadida pelos gafanhotos, sim, pensou, os imigrantes eram gafanhotos. » (p. 98); cette image apocalyptique, qui s'oppose à l'image édénique initiale, annonce donc la fin de la Cecília. La scène où Rossi quitte cette dernière avec amertume est placée sous le signe de la désolation, l'intertexte biblique étant cette fois utilisé à rebours par le narrateur qui se réfère au miracle des poissons et des pains, dont font état les évangélistes Jean, Matthieu, Luc et Marc : "Agora teriam uma noite de tempestade, seria sua despedida. Ele chegara cheio de sonho sob uma chuva fértil, chuva abundante e sem ventos, que engordava a terra. Sairia no meio de um vendaval [...]. " (p. 238); à cause de la tempête, le sol sera jonché de " peixes pequenos e muitos sapos mortos » (p. 238). Et le narrateur de conclure : « Rossi sabia que o vendaval tinha tirado a água dos tanques da vizinhança, dos rios e dos charcos, trazendo junto aqueles peixes, era obra do vento impiedoso [...]. » (p. 239). Le vent, agent du mal ${ }^{83}$, cesse de souffler et d'agiter la mer lorsque le Christ se met à marcher sur l'eau, ce qui n'est pas le cas ici. De plus, nous n'assisterons pas dans ce passage à la multiplication des poissons mais à leur mort, les poissons désignant symboliquement les colons qui abandonnent la Cecília les uns après les autres ; Éloïse Mozzani rappelle que le " Christ est souvent figuré comme un pêcheur et les chrétiens comme des poissons $»^{84}$. Autrement dit, la prophétie d'un monde nouveau ne s'est pas réalisée et Rossi, porteur de la bonne nouvelle révolutionnaire, a échoué dans son entreprise. L'utilisation

${ }^{83}$ Sur ce point, voir Éloïse MOZZANI, op. cit., p. 1767.

${ }^{84}$ Ibid., p. 1445. 
de l'intertexte biblique est habile et riche de sens ici car elle montre que l'espérance messianique est à l'œuvre dans l'utopie. Cependant, le texte littéraire de Sanches Neto s'éloigne, on l'aura noté, du texte biblique qu'il convoque pour mettre à distance le discours utopique : le chemin qui mène à la Terre promise, à l'(im)possible Utopie est semée d'embûches et le prophète de temps meilleurs se heurte à l'incrédulité et à la déception de ses disciples.

En réalité, le problème qu'élude volontiers tout utopiste, c'est l'Homme. Plutôt que de résoudre les problèmes pratiques de la vie en société ${ }^{85}$, l'utopiste préfère en effet inventer des cités idéales en vue d'un bonheur collectif, alors que la nature humaine se joue des systèmes, surtout de ceux qui se veulent parfaits ${ }^{86}$. Il arrive donc un moment où l'utopiste est rattrapé par les problèmes concrets de la vie quotidienne en Utopie ${ }^{87}$, or l'enjeu de tout système utopique est sa crédibilité, sa faisabilité 88 car "sem trazer resultados práticos " (p. 151) le bel édifice utopique s'effondre, raison pour laquelle, à la Cecília, "O sonho estava se desfazendo, era isso, o sonho não tinha resistido àquela vida rude [...]. » (p. 178). Rossi est finalement confronté à un problème incontournable, celui de la nature humaine profonde : "Entrou em seu consultório e ficou pensando nas imperfeições humanas, que destroem os ideais mais nobres. " (p. 99) ; il pense donc que le problème qui empêche la concrétisation de son projet, c'est l'Homme et non pas le système en place, à savoir le système bourgeois capitaliste, ou son système " parfait " élaboré dans son " consultório ", c'est-à-dire dans sa tour d'ivoire, l'utopie n'étant qu'une spéculation intellectuelle. Par conséquent, la matière sur laquelle travaille l'utopiste, comme l'homme de lettres du reste, c'est l'Homme ${ }^{89}$; l'utopiste comprend intuitivement les aspirations profondes de ses semblables : Rossi, par exemple, « entendia o coração dos homens » (p. 133). Mais l'Homme est toujours problématique : "L'utopiste, trop spéculatif, n’a pas assez d'Agapè.

\footnotetext{
$\overline{85}$ Voir à ce sujet Alexandre CIORANESCU, art. cit., p. 93.

${ }^{86}$ Cf. idem : «[...] l'utopie ne pense qu'au bonheur de l'Etat, celui des individus étant considéré comme un sous-produit : elle ne se résout d'ailleurs qu'à son corps défendant à admettre que les collectivités se composent d'individus et, même alors, elle ne saurait admettre que ces individus éprouvent parfois le besoin de se sentir disponibles [pour eux-mêmes]. » (ibid., p. 91-92).

${ }^{87}$ Ibid., p. 108.

${ }^{88}$ Ibid., p. 95, 106, 107, 108.

${ }^{89}$ Ibid., p. 99 ; voir aussi p. 93.
} 
Le Village Anarchie Dans UN AMOR ANARQUISTA, de Miguel Sanches Neto: ...

L'universalisme, caractéristique du théoricien l'emporte trop chez lui sur l'amour des individus. $"^{90}$.

En somme, la solution utopique ignore les problèmes dus à sa mise en œuvre, comme le montre un dialogue entre Rossi et Adele, qui lui demande pourquoi l'anarchisme a échoué (p. 231) ; Rossi lui répond que " - As respostas um dia se gastam " et que c'est " Por medo das perguntas. » (p. 232) qu'il s'est borné à donner des réponses. Ainsi, l'Homme est davantage porté à l'individualisme et au narcissisme qu'au communautarisme car l'enfer, c'est les autres : « [...] tinha sido um sonho juvenil, criar um mundo justo, onde não houvesse dominação, isso era impossível, um homem tinha que pensar primeiro em sua família, [...] quem tinha família não podia pensar só nos outros, o outro não passava de inimigo, pronto para tirar a comida da gente [...]. » (p. 110); on sait aujourd'hui que l'obsession du Même dans le communautarisme et surtout dans le collectivisme, lesquels intègrent seulement " quem quer e tem os mesmos ideais » (p. 24), a produit un effroyable système uniformisant qui nie l'individu pour privilégier les masses, comme le rappelle Philippe Muray :

Devrais-je le redire cent fois, le socialoccultisme est la croyance de l'âge de l'indifférenciation. L'ère où tout le monde est pareil, optiquement, auditivement, audiovisuellement, psychologiquement, métaphysiquement et socialement. Le temps du pareil. Du pareil au même. De la progression vers le pareil. ${ }^{91}$

Il ajoute que dans « la collectivité sans fausse note » ou, mieux, dans le " communautarisme comme fausse note surmontée ", "c'est l'individu qui est une dissonance; quand tout le monde se donnera la main, ça sera une symphonie ». D'autre part, l'Homme est aussi davantage porté au désordre qu'à l'ordre, or " anarquismo não é desordem » (p. 61), raison pour laquelle il faudrait, en définitive, un chef au village Anarchie : "Falta um líder, um líder com idéias de justiça, o homem precisa de alguém que diga o que é certo e o que é errado, e se não se vive sem líder, o anarquismo nunca vai prosperar. É um sonho. Sonho bonito. » (p. 111); dans ce monologue intérieur

\footnotetext{
90 Raymond RUYER, op. cit., p. 112.

${ }^{91}$ Philippe MURAY, op. cit., p. 449 ; sur les dérives du collectivisme, voir aussi Michel ONFRAY, Politique du rebelle - Traité de résistance et d'insoumission, Paris, Grasset \& Fasquelle, 1997, (Le Livre de Poche, Biblio / Essais ; $\mathrm{n}^{\circ}$ 4282), p. 99-100.
} 
de Zéfiro, c'est bien l'utopie anarchiste qui est mise en cause.

Enfin, le contact prolongé avec le monde extérieur a contaminé les membres de la communauté, les rendant incapables de rompre avec leur ancien mode de vie, comme l'a écrit Rossi dans une de ses lettres : " Ainda são movidos pelos preconceitos de séculos de dominação [...], que os contaminou tão completamente, que nem o remédio da vida anárquica pôde curá-los [...]. » (p. 112). D’ailleurs, beaucoup d'anarchistes étaient contre la création de communautés expérimentales car ils pensaient qu'il fallait d'abord combattre l'ordre bourgeois de l'intérieur : "Toute tentative anarchiste ne peut être complètement anarchiste par ce fait que subsiste à côté d'elle l'organisation bourgeoise qui la domine. ${ }^{92}$. Cioranescu insiste également sur les risques liés aux échanges entre la cité idéale et l'extérieur :

[...] les utopistes [...] avaient commis une lourde erreur en n'assurant pas [...] l'étanchéité de leur établissement. L'osmose et les tentations du monde extérieur y jouant librement, on comprend que ces sociétés vouées à la fixité et au bonheur monotone leur aient préféré l'aventure de n'importe quelle contamination..$^{93}$

C'est bien ce qui s'est passé à la Cecília mais Rossi dresse dans ses dernières lettres, non sans une certaine mauvaise foi, un bilan mitigé de son expérience au Brésil :

Não conseguimos por acidentes, por falta de um melhor planejamento, por inexperiência. Mas temos a prova de que é possível, a liberdade plena é algo que se pode conquistar aqui e agora, está ao alcance de todos.

O principal resultado da Cecília foi o amor livre. O fim da família tradicional deve ser o centro da grande revolução. [...]

$[\ldots$

Provámos que é possível este tipo de vida. Quando tivermos condições mais favoráveis, o amor anarquista poderá revolucionar o mundo. (p. 221-222)

${ }^{92}$ Isabelle FELICI, op. cit., p. 81 ; sur cette polémique autour des colonies anarchistes expérimentales, voir aussi p. 20-21, 80.

${ }^{93}$ Alexandre CIORANESCU, art. cit., p. 108-109. 
Le Village Anarchie Dans UN AMOR ANARQUISTA, de Miguel Sanches Neto: ...

Dans la dernière lettre datée du 6 avril 1896, et adressée à l'anarchiste Sanftleben installé en Suisse ${ }^{94}$, il revient sur les causes de son insuccès au sein de la Cecília :

Sobre a razão do fim da Colônia, já disse ao senhor que foi basicamente pela miséria, tivemos que começar um mundo novo sem nada, e com dezenas de pessoas para alimentar. [...]

$[\ldots$

A Colônia, para mim, serviu para provar que sem os laços de família é possível levar vida anarquista, e que o socialismo só será viável se tiver capacidade de produzir bens suficientes, garantindo condições dignas aos trabalhadores; caso contrário, eles preferirão sempre a exploração dos capitalistas. (p. 240-241)

Il est à noter que Miguel Sanches Neto a voulu que son roman s'achève sur une note lyrique et résolument optimiste, et même nostalgique puisqu'à la fin du livre Adele et ses filles, qui se recueillent sur la tombe de Rossi au cimetière de Pise, évoquent l'heureux temps passé à la Cecília, où la vie avait une réelle consistance : «Tudo era mais colorido naquele passado. Era mais vivo, mais real. » (p. 249).

\section{LE REENCHANTEMENT DU MONDE ET LA LITTERATURE COMME ESPACE UTOPIQUE}

Le rêve s'est brisé à la Cecília mais l'Homme a tellement besoin de croire que le réenchantement du monde est possible qu'il est toujours prêt à suivre, malgré les embûches, ceux qui lui promettront un avenir radieux dans une cité harmonieuse, et ce « - Talvez apenas para acreditar. » (p. 26), comme le dit Adele. L'utopiste apparaît en effet aux yeux de ses adeptes comme un sauveur qui les conduit vers la Terre promise. D'ailleurs, dans l'une de ses premières lettres, Rossi se dit confiant dans l'avenir et s'enorgueillit d'être considéré par le Dr. Grilo, entre autres, comme un sauveur qui crée un monde nouveau à partir de rien (p. 32) ; tel un prophète, il est persuadé « que estamos no caminho certo » (p. 103). Une des erreurs commises par les colons est justement d'avoir cru à un sauveur, comme le fait remarquer Rossi : « - Eu nunca tive poderes mágicos. » (p. 232), ré-

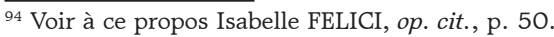


pond-il à Adele au moment où l'expérience de la Cecília touche à sa fin ; la croyance dans les pouvoirs magiques d'un sauveur n'ont jamais rien donné de bon, comme chacun sait. La réponse de Rossi montre au passage que la pensée utopique est une expression spécifique de la pensée magique ${ }^{95}$. Rossi, comme tout utopiste, n'est pas un charlatan ou un odieux manipulateur ; Sanches Neto n'a d'ailleurs pas cherché à ternir son image. Lorsque ses compagnons tournent en dérision le mythe du paradis terrestre, parodiant l'écriture utopique car ils ne croient plus au futur prophétique ( - No paraíso terreno, correrão rios de leite e os peixes virão até nós [...]. », p. 237), Rossi répond qu'il faut agir et faire preuve de détermination pour transformer la société : «- Nada vem até nós [...]. » (p. 237). A la Cecília, il y avait par conséquent ceux qui croyaient trop et ceux qui ne croyaient pas assez. Rossi a simplement péché par excès d'idéalisme, l'idéal cessant, bien sûr, d'être idéal lorsqu'il se réalise : pour reprendre une expression de Michel Onfray, il fait partie de « ceux dont le volontarisme définit l'utopie moins comme l'irréalisable que comme le non encore réalisé ${ }^{96}$. Rossi est présenté en effet comme un homme qui prenait tout au sérieux, "até os seus sonhos » (p. 228); on ne peut donc le faire passer pour un simple idéologue cherchant à manipuler les foules : «- [...] Rossi tem os relatórios dele. Vai continuar acreditando que tudo deu certo, vai fazer a propaganda de suas idéias. » (p. 230). Le discours intérieur d'Adele, capté par le narrateur, vient contrebalancer le point de vue de ce colon aigri, Rossi étant alors dépeint comme un homme qui a constamment « [...] os olhos voltados para o sonho, numa imagem interior que era mais forte do que a realidade, pois a realidade para ele não existia, a realidade era falsa, tão vivos os seus ideais. » (p. 230). Il avait sans doute conservé le romantisme propre à la jeunesse (p. 7) et son seul défaut, peut-être, était qu'il « idealizava bastante » (p. 10).

Rossi n'était certes pas doté de pouvoirs magiques mais «tinha esta crença no poder da palavra » (p. 51) ; en bon idéologue, il croyait donc au pouvoir, à la magie du verbe, comme les hommes de lettres. Il accorde du reste une grande importance à la lecture ${ }^{97}$, associée au

${ }^{95}$ Voir à ce propos Alexandre CIORANESCU, art. cit., p. 99 ; voir aussi Paul RICGUR, L’idéologie et l'utopie, éd. cit., p. 390.

${ }^{96}$ Michel ONFRAY, op. cit., p. 99 ; voir aussi Alexandre CIORANESCU, art. cit., p. 95.

97 Cf. Alain PESSIN : « De manière générale, les anarchistes, qui sont des rêveurs, ont beaucoup

lu. [...] Ils ont donc lu [...] toutes sortes de choses. Outre les textes spécifiquement anarchistes 
Le Village Anarchie Dans UN AMOR ANARQUISTA, de Miguel Sanches Neto: ...

plaisir et au rêve (p. 49, 74) : « escrevia as suas cartas, lia os livros e ficava olhando o céu » (p. 61) ; ainsi, la lecture ouvre des horizons insoupçonnés et infinis, à l'image du ciel, qu'il scrute et où se reflète son idéal, lequel repousse les frontières du réel. En tant qu'individu cultivé, qui s'adonne à la lecture et à l'écriture, Rossi, notons-le au passage, incarne la figure du sage, du " prophète de temps meilleurs », personnage caractéristique du mouvement anarchiste ${ }^{98}$; Adele est d'ailleurs attirée par l'aura du Dr. Rossi : « [...] procurou Rossi, que escrevia em seu quarto [...]. Tinha uma dignidade mesmo com as roupas velhas, parecia um professor [...], era isto que a atraía ? Um pouco, mas também aquele olhar bondoso, a voz calma e firme [...]. » (p. 230). Au moment où elle s'interroge sur la viabilité de l'anarchisme et du socialisme (p. 231), Adele en arrive à la conclusion que le projet utopique de Rossi n'est rien d'autre qu'une construction mentale, ou plutôt verbale, et que, finalement, « - Tudo é um jogo de palavras. » (p. 232) ; cette définition pourrait d'ailleurs s'appliquer à la littérature. Ce point de vue est confirmé par Rossi ; en effet, à la question "Que reste-t-il lorsque l'utopie réalisée tourne à l'échec ? ", il répond : "- Só nos restam palavras. » (p. 232). Ainsi, l'utopie est fiction, comme le fait remarquer Paul Ricœur : « [...] toutes les utopies sont ambiguës : elles prétendent à la réalisation en même temps qu'elles sont des œuvres de fiction et revendiquent l'impossible. "99 $^{99}$; Dubois développe magistralement ce point :

La création utopique est une figure cosmogonique. L'utopiste enfante un royaume en prononçant un discours sur ce royaume. [...] Le discours est discours et la ville cité de papier. Ecrire consiste à verbaliser ses désirs [...]. [...] Cette construction verbale, l'utopiste va la faire passer pour réelle ou pour réalisable : et comme il ne possède que des mots, ce sont des artifices verbaux qui vont suppléer à la réalisation. [...] le discours ne peut agir sur le réel [...] ; il va agir sur la phantasia, la vieille faculté confusioniste,

de Proudhon, Bakounine et Stirner [...], de Kropotkine, Grave ou Reclus [...], l'on peut trouver couramment dans la bibliothèque du militant anarchiste des œuvres de Rousseau, de Voltaire et de Diderot, de Büchner, Darwin, Tolstoï, Ibsen, G. Sand, une large place étant faite à Zola et à Hugo. " (op. cit., p. 51).

${ }^{98}$ Cf. idem : " Et ce souci permanent de culture donne parfois naissance dans les quartiers anarchistes à une figure nouvelle, une figure de sage. [...] il y aura désormais [...] des sages de quartier, hommes doux et rêveurs, prophètes de temps meilleurs [...]. » (ibid.).

${ }^{99}$ Paul RICEUU, Lidéologie et l'utopie, éd. cit., p. 396. 
par les moyens d'artifices destinés à semer la confusion entre les réalités et les signes verbaux. [...]

Le premier subterfuge consiste à faire passer le potentiel et l'irréel - le mode de la supposition - [...] au mode de la réalité : l'indicatif. [...]

$[\ldots \ldots \ldots \ldots \ldots . . . . . . . . .6]$

[...] L'objet est image, l'indicatif signe sa réalité « idéelle », c'est tout. ${ }^{100}$

Par conséquent, l'utopiste ne doit pas être confondu avec l'idéologue manipulateur, qui cherche à duper les esprits. D'ailleurs, la perspicace Adele ne décrit pas Rossi comme un imposteur ou un traître, mais comme un utopiste sincère :

[...] estava ali um homem que vivia seus sonhos e os vivia de forma verdadeira, eram estes que mudavam o mundo, mesmo que depois o mundo voltasse a ser o que sempre fora, vale de lágrimas e de intrigas, mas ele tinha o poder da convicção e da obstinação. Desde aquele dia, tudo que ela desejava era estar junto com homens iguais a ele, que lutavam por algo tão difícil e improvável [...] - manter um ideal era para poucos, Rossi vivia o seu [...], não enganara ninguém, talvez até enganasse a si próprio com esta história toda, só que este tipo de engano nada tinha de traição, era a qualidade maior dos sonhadores. (p. 177)

Adele aurait pu en dire autant de l'homme de lettres ; du reste, Rossi, ne l'oublions pas, s'est essayé à la littérature en publiant un récit utopique, ce qui est très rare dans le milieu anarchiste car « Ce serait [...] céder à nouveau à l'autoritarisme que de proposer [...] des modèles pour la vie. ${ }^{101}$. L'utopiste serait donc sincère alors que l'idéologue serait volontiers calculateur, comme l'écrit Raymond Ruyer : "L'utopie est moins hypocrite que l'idéologie. Quant l'utopiste se dupe, il est pris plus sincèrement et plus candidement à son propre jeu. ${ }^{102}$. On ne peut par conséquent accuser de mensonge ni la littérature ni l'utopie car ni l'une ni l'autre ne cherche à tromper

\footnotetext{
${ }^{100}$ Claude-Gilbert DUBOIS, art. cit., p. 452-454

${ }^{101}$ Alain PESSIN, op. cit., p. 102.

${ }^{102}$ Raymond RUYER, op. cit., p. 54.
} 
Le Village Anarchie Dans UN AMOR ANARQUISTA, de Miguel Sanches Neto: ...

personne. Il est à la fois tentant et pertinent d'établir des rapprochements entre ces deux catégories de l'imaginaire, l'utopiste se doublant d'un poète ${ }^{103}$. Ainsi, l'utopiste et l'homme de lettres voient un autre monde ${ }^{104}$ où l'on évolue par la seule force de l'imagination : la plupart des utopies sont, du reste, des utopies littéraires dont les deux tiers ont été écrites au XIX ${ }^{e}$ sècle $^{105}$. Comme on peut le constater à la lecture du roman de Sanches Neto, il existe des affinités entre l'utopie et la littérature : toutes deux tendent en effet vers l'imaginaire, la spéculation, le rêve et puisent leur force de persuasion dans la magie du verbe.

En attendant le Grand Soir, entendons la révolution, le réenchantement du monde passe par la littérature : à ce propos, la partie épistolaire, importante dans Um Amor Anarquista, montre que l'utopie se donne d'abord à lire par ceux qui veulent quitter l'Italie afin de réaliser leur rêve : elle s'offre donc d'abord comme un pur récit. Mais la solution littéraire n'est qu'une incitation à l'action car les livres ne font pas tout, ainsi que le suggère Lorenzo (p. 94), et la littérature à elle seule est impuissante à transformer le monde, ce dont témoigne de manière tout à fait éclairante le parcours du Dr. Rossi. Ce dernier vit un rêve, il vit son roman : «- [...] Escrevi manifestos, romance de tese, agora quis viver dentro de um romance. » (p. 26) ; la frontière entre l'utopie et la littérature est par conséquent bien ténue. Si Rossi a fait tout ce qu'il a fait et s'il a écrit tout ce qu'il a écrit, c'est au moins pour continuer de croire (p. 26). Rendre l'homme disponible à la contemplation de la poésie du monde, voilà ce que proposent la littérature et l'utopie comme horizon de l'existence humaine : "Quando nossa população crescer, haverá ócio para as artes, para a leitura, para o namoro ou apenas para contemplar os entardeceres, que não nos doerão tanto, pois a solidão estará afastada $e o$ pôr-do-sol poderá ser apenas poesia. » (p. 49-50; c'est nous qui soulignons).

${ }^{103}$ Ce n'est pas un hasard si Michel ONFRAY présente Fourier comme un poète (op. cit., p. 100).

${ }^{104}$ C'est ce qu'Alexandre CIORANESCU appelle " la fiction d'un monde parallèlle », qui fonctionne comme une revanche sur les difficultés et les frustrations de l'existence humaine (art. cit., p. 94-95).

${ }^{105}$ Voir à ce propos Lewis MUMFORD, op. cit., p. 99. 


\section{CONCLUSION}

Miguel Sanches Neto signe ici un roman sociologique inspiré d'un fait réel, où il raconte la lutte de la classe ouvrière contre la bourgeoisie et la vie en communauté à la Cecília, colonie anarchisante, tout en recourant à un expédient romanesque somme toute classique : l'amour, matière à roman que lui fournit d'ailleurs le livre de Rossi, " a poesia deste caso de amor » (p. 205) apportant une note lyrique au récit qui nous occupe. Le travail de documentation, et donc de mémoire, de Miguel Sanches Neto mérite par ailleurs d'être souligné ; ce souci de véracité est du reste le meilleur moyen de rendre hommage à l'esprit de Rossi ; l'esprit qui a régné à la Cecília permet à l'écrivain de créer véritablement une atmosphère. Sanches Neto a en effet reconstitué fidèlement le parcours et l'expérience anarchisante du Dr. Rossi, qui sont liés à la fois à l'histoire de l'anarchisme, lequel se répand en Europe ${ }^{106}$ et au Brésil (p. 68-69), et à l'immigration massive au Brésil au XIX ${ }^{\mathrm{e}}$ siècle. L'auteur rappelle les difficultés matérielles et institutionnelles auxquelles se sont heurtés les anarchistes à cette époque-là. N'oublions pas qu'au XIX ${ }^{e}$ siècle, dans la presse comme dans les romans, le mot " anarchie » était affecté d'une connotation péjorative. L'expérience de Rossi correspond d'ailleurs à un déferlement de violence car dans les années 1880 et 1890 l'anarchisme, qui se constitue alors en mouvement social autonome ${ }^{107}$, s'engage dans la lutte sanglante encouragée par la presse anarchiste ${ }^{108}$, ce qui entraînera une vague de répression. L'utopie, quant à elle, a été stigmatisée par Marx qui voyait en elle une forme d'aliénation ou, en tout cas, d'immaturité ${ }^{109}$, raison pour laquelle il a qualifié

\footnotetext{
$\overline{106}$ Voir à ce propos Alain PESSIN, op. cit., p. 213-214.

${ }^{107}$ Ibid., p. 55,172, 214.

${ }^{108}$ Ibid., p. 136, 154, 173, 214.

109 Selon Paul RICEUUR, les « marxistes ont toujours affirmé que le capitalisme doit parvenir à un certain niveau pour que se développe une situation révolutionnaire : la promotion de l'utopie correspond au stade de l'immaturité. "; en conséquence, l'utopie " est décrite négativement comme un défaut de maturité [...]. ». Ainsi, cette " pensée qui prétend se projeter en avant est en fait un retour en arrière à quelques grandes 'fantaisies' littéraires et sociales du passé [comme l'Utopie de More ou La Cité du Soleil de Campanella]. [...] Engels appelle 'poésie sociale' une forme au moins de cette pensée utopique. Engels voulait ainsi la caractériser de façon négative [...]. ». Et l'essayiste d'ajouter : «[...] l'utopie n'est pas seulement un rêve, mais un rêve qui veut se réaliser. Il se dirige vers la réalité et il la brise. L'intention utopique est sans aucun doute de changer les choses, et on ne peut donc pas dire comme Marx [...] qu'elle n'est qu'une façon d'interpréter le monde et non de le transformer. Au contraire, la pensée utopique veut changer la réalité. " (L'Idéologie et l'Utopie, éd. cit., p. 377, 378 ; voir aussi Lewis MUMFORD, op. cit., p. 202).
} 
Le Village Anarchie Dans UN AMOR ANARQUISTA, de Miguel Sanches Neto: ...

l'utopie et l'idéal de "réactionnaires $~^{110}$; Engels a lui aussi critiqué les utopies socialistes, comme celle de Fourier ${ }^{111}$. La campagne de dénigrement qu'ont subie les membres de la Cecília, dont Sanches Neto se fait l'écho, en est une illustration. Um Amor Anarquista peut se lire aussi comme l'épopée des immigrants partis à la conquête de la terre brésilienne, autrement dit comme l'épopée sublime, faite de sang et de rêve, d'un Brésil en construction, l'utopie jouant un rôle important, comme le suggère Fernando Ainsa ${ }^{112}$, dans l'émigration vers le Brésil et les autres pays du Nouveau Monde ainsi que dans la formation de la nation brésilienne et des nations américaines d'une manière générale. En somme, Um Amor Anarquista nous offre une épopée du rêve.

Composé de deux plans, opposant en miroir la pratique anarchisante et le discours sur cette pratique de l'idéologue Giovanni Rossi, ce récit de Sanches Neto passe de la description, par un narrateur extérieur et omniscient le plus souvent, de la vie au quotidien dans la colonie à la propagande contenue généralement dans les lettres de Rossi, autrement dit des difficultés et des tensions à l'espoir, qui s'amenuise, de concrétiser cette utopie libertaire ; le récit oscille par conséquent entre le rêve et le cauchemar, entre le paradis et l'enfer. Cette technique narrative invite habilement le lecteur à une distance critique vis-à-vis de l'(im)possible utopie et de tout discours purement idéologique; le monologisme politique patent dans les lettres de Rossi entre ainsi en conflit avec le discours polyphonique qui caractérise le reste du récit où les personnages expriment, parfois par la voix du narrateur hétérodiégétique, leurs opinions, souvent discordantes. Cette stratégie narrative permet donc de structurer une vision plurielle, contrastée de l'expérience libertaire menée par Rossi en terre brésilienne.

Cette expérience anarchisante a tourné à l'échec, comme toutes les utopies réalisées au XIX ${ }^{e}$ siècle $^{113}$, et il ne reste aujourd'hui quasiment rien de la Cecília mais le rêve n'est pas mort, grâce à la

\footnotetext{
${ }^{110}$ Roger MUCCHIELLI, Le mythe de la cite idéale, Paris, P.U.F. « Bibliothèque de Philosophie Contemporaine ", 1960, p. 168.

${ }^{111}$ Sur les connotations péjoratives du mot « utopie » et sur les critiques de Marx et Engels à l'égard des utopies sociales ou socialistes, voir Jean MONTENOT, art. cit., p. 3, 12, 13.

112 Voir à ce propos Fernando AINSA, « Utopie, terre promise, émigration et exil », art. cit., p. 59.

${ }^{113}$ Voir à ce propos Alexandre CIORANESCU, art. cit., p. 108.
} 
littérature qui le ranime dans Um Amor Anarquista, par exemple. Sous l'évocation de l'échec de la célèbre colonie perce la discrète nostalgie d'un monde libre, parfait et heureux, toujours à reconstruire : « Triste anarquia. Triste Cecília. É duplamente triste que me encontro hoje, mas ainda forte e disposto para recomeçar. ", soupire le fondateur de la Cecília (p 112) ; comme le montre la trajectoire de Rossi, qui après la déception se raccroche à son rêve, l'utopie s'épuise dans sa propre réalisation, allant de frustration en frustration : c'est un éternel recommencement, une sorte de fuite en avant effrénée, un piège, comme le note Fernando Ainsa : "C'est là le 'revers de la médaille', la répétition du schéma fatal de l'utopie : 'Le bonheur persiste à être toujours plus loin, là où l'on n'est pas.' »" ${ }^{114}$.

L'utopie serait en quelque sorte une maladie juvénile dont l'Homme ne guérirait jamais ; pour reprendre l'image médicale utilisée par Muray, c'est une fièvre qui le reprend soudain ${ }^{115}$. Par ailleurs, l'aventure utopique traduit toujours une exigence de bonheur ${ }^{116}$ : « Rossi sentia-se contente [...], pensando na felicidade : ela só podia ser conquistada com o corpo, e se encontrava, para ele, no trabalho rural. » (p. 42) ; on retrouve ici le goût de Rossi pour le bonheur bucolique. Ainsi, l'utopiste attend inexorablement l'avènement du règne de la beauté et de l'éternelle jeunesse, beauté et jeunesse se confondant dans le récit de Sanches Neto (p. 157). L'utopie, et tout particulièrement l'anarchisme, entendent œuvrer à la grande libération $^{117}$ qui permettra à l'individu de contempler la poésie du monde ( $\mathrm{p}$. 49-50); c'est le but visé aussi par la littérature. Etre disponible pour soi ${ }^{118}$, voilà l'enjeu de l'utopie, comme le note Lewis Mumford : " Para o utopiano, o prazer supremo está em cultivar o espírito ; as horas livres do povo, tal como as dos intelectuais, são passadas na biblioteca e no escritório. ${ }^{119}$. Selon Alain Pessin, l'anarchiste est « un éternel enfant à qui le monde s'ouvrira comme un merveilleux

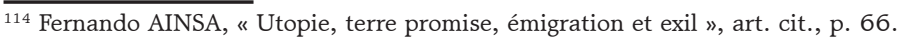

115 Voir Philippe MURAY, op. cit., p. 232.

${ }^{116}$ Souvenons-nous que Thomas More a donné aussi à son île le nom d'Eu-topie pour la présenter d'emblée comme l'île du bonheur ; voir à ce propos Simone GOYARD-FABRE, "Introduction ", in Thomas MORE, L'Utopie ou le Traité de la meilleure forme de gouvernement, présenté et annoté par Simone Goyard-Fabre et traduit par Marie Delcourt, Paris, Flammarion, 1987, p. 17, n. 1. Voir aussi Jean MONTENOT, art. cit., p. 4.

117 Sur ce point, voir Alain PESSIN, op. cit., p. 89.

${ }^{118}$ Voir à ce sujet Alexandre CIORANESCU, art. cit., p. 90.

${ }^{119}$ Lewis MUMFORD, op. cit., p. 73.
} 
Le Village Anarchie Dans UN AMOR ANARQUISTA, de Miguel Sanches Neto: ...

champ d'aventures et pour qui toute étape d'existence sera jeu nouveau, invention, création ", "sa seule sanction étant le lieu heureux et enfin retrouvé de l'homme à lui-même et au monde par le détour de l'œuvre $»^{120}$ (p. 104, 105) ; et de conclure : "C'est alors, dit-on, que 'l'art contaminera la vie' ${ }^{121}$ (p. 105). Autrement dit, l'utopie, comme l'anarchisme qui fait la promotion de la «vie en jeu $»^{122}$, ne trouvera son aboutissement que lorsque l'art s'incarnera dans la vie même, l'art et la vie ne faisant qu'un ${ }^{123}$.

Malgré le naufrage des utopies réalisées, le rêve utopique demeure vivant en l'homme : il s'agit là d'un rêve primordial, consubstanciel à notre humanité. Lorsque ce rêve se défait en se réalisant, il ne reste plus que la littérature, lieu privilégié de l'utopie et du rêve ; ainsi la littérature et l'utopie, expression d'un amour universel, donnent de la poésie au monde. Par ailleurs, l'utopie et l'amour sont deux ressorts de la transformation de l'Homme et, par conséquent, du monde : voilà la lecture généreuse que l'on peut faire du roman de Sanches Neto, qui répond à sa manière à un besoin d'utopie dans un monde désenchanté où d'aucuns ont décrété la fin des idéologies et la mort de l'utopie, bref, la fin de l'histoire ${ }^{124}$.

L'utopie cependant continue de faire palpiter les cœurs comme en témoignent la réédition ${ }^{125}$ la même année au Brésil de Um Amor Anarquista, la publication de sa traduction en Argentine et le fait que l'expérience de la Cecília ait servi de matière à un film franco-italien de Jean-Louis Comolli en 1976, à un roman brésilien d'Afonso Schmidt paru en 1942 et réédité en 1980 et, enfin, à une pièce de théâtre brésilienne en 1987. Un tel engouement pour l'histoire de la Cecília traduit la fascination des Brésiliens pour l'utopie, signalée du reste

\footnotetext{
${ }^{120}$ Alain PESSIN, op. cit., p. 104-105.

= Ibid., p. 105 .

122 Ibid., p. 111.

${ }^{123}$ Cf. Alix LARGE : " La question des rapports art-vie est immanquablement associée à l'émergence des avant-gardes politiques au $\mathrm{XIX}^{\mathrm{e}}$ siècle et à la volonté de leurs théoriciens de déterminer ce qui distingue les forces révolutionnaires, participant à l'avènement d'une société nouvelle, de celles qui ne le sont pas et qui servent les 'intérêts bourgeois'. Dès lors, tous condamnent l'artiste moderne, rejeton du capitalisme et de l'individualisme et rêvent d'un art social, fait pour et par le peuple. » (op. cit., p. 58 ; voir aussi p. 59 et suiv.)

124 Voir à ce sujet Georges LABICA, art. cit., p. 34, et Paul RICEUR, Lidéologie et l'utopie, éd. cit., p. 370. Sur le bilan mitigé de l'aventure utopique, voir Eduardo PORTELLA, « O testamento da utopia », Jornal de Letras, Artes e Ideias, n 754, 25 août-7 sept. 1999, p. 35.

${ }^{125}$ Une troisième édition devrait paraître prochainement.
} 
par Eduardo Portella ${ }^{126}$, et d'une manière générale celle de l'Homme d'aujourd'hui, en proie à l'angoisse de la fin des certitudes ${ }^{127}$.

Malgré l'échec, Rossi et d'autres seront transformés par l'expérience vécue à la Cecília car l'individu est toujours transformé par ce qu'il aime, par ce en quoi il a foi, comme ces femmes qui, en pratiquant l'amour libre à la Cecília, se transforment aux yeux de leurs enfants et de leurs maris (p. 217), d'où cette citation de l'anticonformiste Joseph Brodsky, placée en épigraphe du livre : "Somos sempre modificados pelo que amamos ».

Enviado em: 06/07

Aceito em: 02/08

${ }^{126}$ Voir Eduardo PORTELLA, art. cit., p. 35.

${ }^{127}$ D'après Georges LABICA, le besoin d'utopie « pose l'homme comme être de projet, de tension vers le futur » (art. cit.) ; partant, ce besoin d'utopie est un besoin primordial chez l'Homme. 